NBER WORKING PAPER SERIES

\title{
THE ROLE OF HOSPITAL AND MARKET CHARACTERISTICS IN INVASIVE CARDIAC SERVICE DIFFUSION
}

\author{
Jill R. Horwitz \\ Charleen Hsuan \\ Austin Nichols \\ Working Paper 23530 \\ http://www.nber.org/papers/w23530 \\ NATIONAL BUREAU OF ECONOMIC RESEARCH \\ 1050 Massachusetts Avenue \\ Cambridge, MA 02138 \\ June 2017
}

The authors thank Stephanie Tomlin, MIHCL, MPA and Weiping Zhou, MS in the Data Analytic Core at The Dartmouth Institute (supported by the National Institute on Aging (PO1-AG19783)) for data support, and Christopher Snyder and an anonymous reviewer for helpful comments. We also thank Jessi Bulaon, Henry Kim, Olivia Metcalfe, Matthew McCabe, Lynn McClelland, Ben Nyblade, and Matthew Parson for research assistance. Horwitz thanks the UCLA School of Law for summer research support. The views expressed herein are those of the authors and do not necessarily reflect the views of the National Bureau of Economic Research.

NBER working papers are circulated for discussion and comment purposes. They have not been peer-reviewed or been subject to the review by the NBER Board of Directors that accompanies official NBER publications.

(C) 2017 by Jill R. Horwitz, Charleen Hsuan, and Austin Nichols. All rights reserved. Short sections of text, not to exceed two paragraphs, may be quoted without explicit permission provided that full credit, including $(\odot$ notice, is given to the source. 
The Role of Hospital and Market Characteristics in Invasive Cardiac Service Diffusion

Jill R. Horwitz, Charleen Hsuan, and Austin Nichols

NBER Working Paper No. 23530

June 2017

JEL No. I1,I11,I18,L1,L13,L2,L3,L8

\begin{abstract}
Little is known about how the adoption and diffusion of medical innovation is related to and influenced by market characteristics such as competition. The particular complications involved in investigating these relationships in the health care sector may explain the dearth of research. We examine diagnostic angiography, percutaneous coronary interventions (PCI), and coronary artery bypass grafting (CABG), three invasive cardiac services. We document the relationship between the adoption by hospitals of these three invasive cardiac services and the characteristics of hospitals, their markets, and the interactions among them, from 1996-2014. The results show that the probability of hospitals adopting a new cardiac service depends on competition in two distinct ways: 1) hospitals are substantially more likely to adopt an invasive cardiac service if competitor hospitals also adopt new services; 2) hospitals are less likely to adopt a new service if a larger fraction of the nearby population already has geographic access to the service at a nearby hospital. The first effect is stronger, leading to the net effect of hospitals duplicating access rather than expanding access to care. In addition, for-profit hospitals are considerably more likely to adopt these cardiac services than either nonprofit or government-owned hospitals. Nonprofit hospitals in high for-profit markets are also more likely to adopt them relative to other nonprofits. These results suggest that factors other than medical need, such as a medical arms race, partially explain technological adoption.
\end{abstract}

Jill R. Horwitz

University of California Los Angeles

School of Law

Box 951476

Los Angeles, CA 90095-1476

and NBER

horwitz@law.ucla.edu

Charleen Hsuan

Department of Health Policy and Administration

The Pennsylvania State University

604 Ford Building

University Park, PA 16802-6500

charhsuan@nber.org
Austin Nichols

Abt Associates

austinnichols@gmail.com 


\section{Introduction}

Innovation is often an important product of competition. Yet, although researchers have studied some causes of the adoption and diffusion of medical innovations, little is known about how that adoption is related to and influenced by market characteristics such as competition. The relationships between competition and technological innovation (Aghion et al., 2014) and the diffusion of innovation (Shapiro, 2012) are difficult to specify, even in markets for ordinary goods. The particular complications involved in investigating these relationships in the health care sector may explain the dearth of research.

Because medical care is so different from ordinary market goods, it is even more difficult to characterize competitive medical markets and to predict or identify how competition affects innovation and diffusion of medical technology than in the case of other goods and services. Unlike other goods, in which the concentration of suppliers in populated areas helps consumers benefit from low prices, dispersion of medical suppliers is critical for patient access. In addition, medical care is often provided by hospitals, which are highly regulated, are organized as different types of legal entities, compete as local monopolies and oligopolies, receive payments from third parties instead of patients, and receive reimbursements based on governmentregulated prices rather than market demand. Further, prices are not posted, and are typically unknown both to patients and medical staff. Unsurprisingly, there is no general theory of competition in such markets, much less a theory to explain the effects of such competition on technology development and diffusion. Despite these challenges, providing appropriate access to care, controlling costs, and insuring the quality of medicine all critically depend on understanding how and why medical providers adopt technology. Therefore, we document 
important empirical regularities that provide evidence of the effects of hospital competition on the provision of care.

To investigate the connection between competition and medical technology diffusion, we study the relationship between the adoption of invasive cardiac services by hospitals and the characteristics of those hospitals, their markets, and the interactions among them. The bulk of payments for invasive cardiac services at hospitals come from government payers, making it unlikely that differences in demand because of price explain our results. In addition, we include rich controls for market demographics that are strong predictors of the need for cardiac interventions.

We focus on the adoption of three types of invasive cardiac services from 1996-2014: diagnostic angiography, percutaneous coronary interventions (PCI), and coronary artery bypass grafting (CABG). These are particularly important services to study for several reasons. First, these services are meant to treat heart attacks (acute myocardial infarctions or AMIs), a leading cause of morbidity and mortality around the world and in the United States, making the interventions critical for a large part of the national and world populations. Second, AMI is one of the five most expensive inpatient conditions to treat; in 2013 AMI accounted for approximately $\$ 12$ billion or 3.2 percent of national aggregate costs for all hospitalizations and 602,000 hospitalizations (Torio and Moore, 2016). Understanding the diffusion of treatments would help develop interventions to control their costs. Third, there is evidence that for some patients, medical therapy alone is as effective as the far more expensive and invasive PCI. Finally, there is large variation in treatment of cardiovascular disease by geographic area, and those differences are "predominantly driven by differences in local capacity and local medical decision making" (Wennberg, 1999, preface). These findings suggest that the diffusion and use 
of medical technology are driven, at least in part, by factors other than medical need. There is room for policy interventions that guide diffusion to increase the efficiency of medical care.

Previous research has demonstrated that by 2000 , almost 80 percent of the U.S. population lived within 60 minutes of a hospital with PCI (Nallamothu et. al., 2006). Given this coverage, there has been little room for new hospitals to increase geographic access to care. Previous research has shown that hospitals are most likely to introduce new invasive cardiac services when neighboring hospitals already offer such services, and this diffusion has not improved geographic access to care, but rather duplicated existing services (Horwitz et al., 2013; Concannon et al., 2012). In fact, because hospitals are more likely to adopt a service if nearby hospitals already offer it, simulations suggest that more people would have had greater geographic access to care if, instead of allowing hospitals to decide whether to adopt a new service, new services had been randomly distributed to existing hospitals that did not already offer them (Horwitz et al., 2013). Strategic selection of hospitals to newly offer care would improve access more than random distribution, so the pattern of endogenous selection we find here is doubly inferior to the first best.

This paper builds on those findings in several important ways. First, unlike previous research which uses fixed distances, geopolitical designations, or hospital referral regions to define markets, we define hospital markets by travel time to the hospital based on medical recommendations of how quickly patients suffering the symptoms of a heart attack should be treated. Second, we consider hospital and market characteristics related to adoption of new technology. The latter include demographic characteristics of the population in each hospital's market, which are important to consider because these characteristics are associated with the probability that residents are insured, the type of insurance, and the costs and profit margins of 
medical treatment. The services studied here are both expensive to provide and, on average, profitable for hospitals, making the demographics of the patient population particularly significant for a hospital's bottom line. Third, we focus on the role of the legal ownership of hospitals - nonprofit, for-profit, and government. Here we consider the role of ownership in a hospital adopting new services as well as the role of the market mix and the interaction between the two, factors that play important roles in the decisions of hospitals to offer medical services (Horwitz and Nichols, 2009). Finally, our study period, 1996-2014, is lengthy.

We find the probability of hospitals adopting a new cardiac service depends on competition in two distinct ways. First, hospitals are substantially more likely to adopt an invasive cardiac service (defined as performing 11 or more such procedures per year) if competitor hospitals (defined as those within an hour drive of the observation hospital) also adopt new services. However, we also find that hospitals are less likely to adopt a new service if a larger fraction of the nearby population already has geographic access to the service at a nearby hospital (defined as residents that live within an hour drive of the observation hospital also live within an hour of another hospital offering that service).

Although these two effects are offsetting, the response of hospitals mimicking nearby adoption despite that hospital's patient market already having access to care has the net effect of duplicating access rather than substantially expanding access to care. That is, for a hospital which has not yet adopted a particular invasive cardiac service, the adoption of the service by nearby hospitals increases the proportion of the population that has access, which modestly reduces the probability a given hospital adopts it, but the local increase in adoptions dominates, leading to a net increase in its probability of adoption. These results suggest that hospitals are 
engaging in a medical arms race rather than offering services that would increase geographic access to care.

Moreover, during the study period, for-profit hospitals are considerably more likely to adopt the three services studied here than either nonprofit or government-owned hospitals. Nonprofit hospitals also are more likely to adopt these cardiac services if they are in a high forprofit market, relative to nonprofit hospitals in a market with lower for-profit penetration, However, tests regarding the relationship among the ownership of an individual hospital and whether competitors adopt a service yield few consistent or statistically significant results. In sum, the evidence is consistent with previous research on geographic variation in health care and suggest that factors other than medical need explain technological adoption.

\section{Background}

Technology progress in medicine has saved many lives. Cutler (2004), for example, has shown that technological innovation and associated spending has been, on average, well worth the costs. However, other researchers have questioned the value of rapid development and diffusion of medical technology. For example, Robinson and Luft (1985) characterized new service adoption as the result of a medical arms race, one that leads to inefficient investment in medical technology. Scholars later found evidence that the acquisition of new medical technology was driven by, among other factors, a hospital's attempt to maintain or expand a local market (Hillman et al., 1987) and the importance a hospital attaches to being a technological leader (Teplensky et al., 1995). Skinner \& Staiger (2015, pg. 3) made progress in reconciling these views - that technology adoption led to improvements in health and that technology adoption was caused by, at least in part, nonmedical reasons - in arguing that health 
care "improvements are largely associated with the adoption of effective treatments, rather than more factor inputs per se."

Indeed, researchers have found that expensive and profitable medical technology diffuses before there is a strong case for its widespread use. For example, Ladapo et al. (2009) found that 64-slice computed tomography was widely adopted by hospitals for its role in angiography for cardiac patients despite the lack of evidence regarding its effectiveness for that purpose, raising concerns about haphazard acquisition.

The services we focus on here — diagnostic angiography, PCI, and CABG—provide apt examples of this phenomenon found in health care more generally. Diagnostic cardiac angiography is a procedure that involves the placement of a catheter through veins or arteries and into the heart to inject a contrast agent, taking a picture with an $\mathrm{x}$-ray machine, and evaluating whether the patient has a blockage in a coronary artery (Lange and Hillis, 2003). PCI, commonly called coronary angioplasty, is a procedure that opens coronary arteries that have been blocked by plaque. A doctor inflates a balloon at the tip of a catheter to open an artery and may place a stent to keep the artery open. CABG, commonly known as open heart surgery, is a surgery to allow blood to flow to the heart by using a healthy artery or vein from a patient and grafting it into a coronary artery so as to go around the blocked portion of the artery.

These services have provided great value for some patients, but not for all (Chandra \& Skinner, 2012). On the one hand, advances in the prevention and treatment of cardiovascular disease, including the services studied here, have led to striking improvements in morbidity and mortality. For example, from the mid-1970s through the early 2000s, age-adjusted death rates from coronary heart disease declined by more than 60 percent (Weisfeldt and Zieman, 2007). Cutler and Kadiyala (2003) estimate that about one third of these reductions can be explained by 
invasive procedures. In another estimate, Cutler and McClellan (2001) conclude that approximately 70 percent of the survival improvement in cardiac mortality between 1984 and 1998 was attributable to technological change.

On the other hand, there is evidence of considerable geographic variation in treatment. Matlock et al. (2013) found that "the 2007 rate of coronary angiography varied nearly 6-fold from 6.8 per 1000 Medicare fee-for-service (FFS) beneficiaries in Honolulu, [Hawaii], to 39.8 per 1000 in Gulfport, [Mississippi]" (p. 3). In addition, in 2003, "[r]ates varied by a factor of five, from 1.9 per 1,000 enrollees to 9.5.” (Center, 2005, p. 9).

There is also evidence of overuse. For example, a meta-analysis of randomized controlled trials evaluating outcomes of treatment for stable coronary artery disease with PCI compared to medical therapy concluded, "Initial stent implantation for stable coronary artery disease shows no evidence of benefit compared with initial medical therapy for prevention of death, nonfatal myocardial infarction, unplanned revascularization, or angina" (Stergiopoulos and Brown, 2012 at p. 312; Boden, 2012; Stergiopoulos et al., 2014). Although PCI volume declined after the publication of these results, many patients continued to receive PCI for stable coronary artery disease (Howard and Shen, 2014). In addition, findings that high spending is not well correlated with mortality and readmission outcomes in studies that control for population characteristics (Skinner et al. 2006) suggest that there is considerable room for reform to eliminate wasteful and unnecessary care. On the other hand, there is also evidence that higher spending hospitals perform more procedures in the first part of a hospital stay, leading to higher cost and higher short-term mortality but dramatically lower long-term mortality (Doyle et al., 2015). 
Service diffusion may also lead to reductions in the volume of procedures performed at individual hospitals and related reductions in quality. Professional guidelines recommend against the provision of cardiac interventions by low-volume physicians or at low-volume cardiac centers, although those guidelines recognize the complicated and potentially offsetting relationship among institutional and individual operators. (Levine et al., 2011). The positive, albeit attenuating, association between volume and outcomes (Ross et al., 2010) suggests that diffusion concentrated within hospital markets may undermine the effectiveness of the treatments studied here. That is, it may be optimal to perform a more limited number of interventions in a more restricted set of cases in a broad geographic area, but outcomes may be better as more interventions are performed in a location, suggesting that the concentration of procedures in a smaller number of hospitals is better for patients.

In fact, some researchers have found that lower volume occurs in markets where hospitals have begun performing CABGs, and that such low volume has led to increased mortality (Wilson, 2007). However, others have found that improvements in the quality of technology, implementing safeguards like checklists, and physician skill have led to decreased CABG mortality overall. (Finks, 2011). Similarly, Ho (2002) found that as hospitals developed staff capacity to provide percutaneous transluminal coronary angioplasty (PTCA), they achieved substantial reductions in inpatient mortality and emergency bypass surgery. Yet, hospital procedure volume was also associated with a small positive effect on outcomes. Ho concludes that centralizing PTCA by offering it at fewer hospitals could lower costs, but may not have a strong effect on quality. Nonetheless, in an effort to improve quality, there have been calls for concentrating AMI treatment to a limited number high quality, centralized providers that offer PCI treatment within a region. (Chen et. al., 2010). 
Finally, these services are quite costly and, to the extent that they are unnecessary, reducing inappropriate provision could lead to large savings. Cardiovascular disease accounts for 17 percent of national health expenditures; given the aging of the U.S. population, the direct costs of treating cardiovascular disease are predicted to triple from $\$ 273$ to $\$ 818$ billion, in 2008 dollars, between 2010 and 2030 (Heidenreich et al., 2011).

\section{Data and Market Definitions.}

\subsection{Data and Descriptive Statistics}

Data on hospital characteristics are from the American Hospital Association's Annual Surveys of Hospitals (AHA) 1996-2014. We include all non-federal, general medical and surgical hospitals and heart hospitals in the continental United States, including those in the District of Columbia. We exclude children's hospitals and hospitals for which driving times to nearby residential zip codes could not be computed (including several rural cases, and one hospital on an island). We identified the longitude and latitude of each hospital from the AHA or, if the AHA coordinates were missing or differed among years for the same address, we identified the coordinates using Google maps.

To determine whether a hospital treated any patients with AMI and whether a hospital provided any of the three services examined here, we rely on data from Medicare Provider Analysis and Review (MedPar) files for 100 percent of Medicare beneficiaries who received hospital inpatient services 1996-2014. The MedPar dataset included only fee-for-service beneficiaries who were eligible for both Medicare Part A and B and were also U.S. residents. Because of restrictions that forbid using federal data with values smaller than eleven in a cell, we coded a hospital as having treated patients with AMI if they treated at least eleven patients in a year with an International Classification of Diseases-9 (ICD-9) primary diagnosis code for AMI 
(ICD-9 Codes 410.00-410.92). We identified a hospital as providing a service in a given year if that hospital billed the Centers for Medicare and Medicaid Services for at least eleven procedures to Medicare beneficiaries, using the following ICD-9 codes: diagnostic angiography (37.21 through 37.23); PCI (depending on the year 36.01-.02; 00.66; 36.05-36.07); and CABG (36.1036.19). Once a hospital is coded as providing a service, we assume the hospital continues to provide the service for as long as it is in the sample, a reasonable assumption given the costs of starting new invasive cardiac services. We coded all other hospitals as not treating patients with an AMI diagnosis or as not providing one or more of the invasive cardiac services studied here. Adoption is defined as the first year after 1996 in which a service is offered.

We identified the centroid of every zip code tabulation area (ZCTA) using shape files available from the U.S. Census Bureau for the 2010 Census. Demographic data for each ZCTA are from the American Community Survey (2010-2014) and the U.S. Census (2000). We attributed the 2010-14 ACS to 2012. We then interpolated and extrapolated from these data to all years in the sample using a log or logit scale for demographic variables that were counts or percentages, respectively.

Driving distances are primarily from Google maps and, secondarily, from Open Source Road Mapping System (OSRM). We relied on OSRM to estimate approximate travel times and distances based on the closest road only when Google Maps did not estimate driving distance, such as when the centroid of a ZCTA lies in a rural area without roads, on an island, or in a body of water.

\subsection{Market Definitions and Competitor Attributes}

Our definition of geographic markets differs from others in health economics research. Previous researchers typically use political configurations such as counties or, more recently, 
hospital referral regions. The former do not track actual markets for care well (Wennberg, 1999). Although hospital referral regions are an improvement over using political areas to define health care markets, they define markets based on the actual use of medical services at hospitals and not the markets that would best serve patients. Because we are interested in how competition may or may not produce access to medically-indicated care in this project, which endogenously affects actual use patterns, we use a definition of market based on a potential patient's travel time to each hospital.

We identified each hospital's market to include all the residents of ZCTAs, the centroid of which is sixty minutes or shorter driving time in a car to the hospital. We chose sixty minutes based on medical guidelines recommending the maximum amount of time from a patient's first contact with emergency medical personnel to treatment and the total amount of time from symptoms to treatment that produce the best medical outcomes. More specifically, although medical authorities often refer to a "first golden hour" in which myocardial infarction can be treated with the best results (Boersma et. al., 1996), therefore making the sixty-minute driving time too long for the best results, medical recommendation recognize the difficulty of such rapid treatment and tend to include longer times. For example, for primary PCI, some sources report that the "[b]est clinical outcomes...[are] achieved within 120 minutes after symptom onset." (Bates and Jacobs, 2013, p. 890). Bates and Jacobs (2013) recommended a maximum "door-toballoon" time of 90 minutes. Meeting this standard has become the focus of national quality improvement initiatives as well as quality markers for CMS reimbursement (Menees et al., 2013). In 2008, median time between arrival at the hospital and treatment was 76 minutes for patients with acute ST-elevation myocardial infarction (STEMI) who are undergoing percutaneous coronary intervention (Flynn et. al., 2010), which represented an improvement over 
past years. That implies that during our study period, fewer than half of patients with STEMI were treated within the time recommended by guidelines (Bradley et al., 2006). Moreover, mean symptom duration is two hours before first medical contact (Bates and Jacobs, 2013), i.e. patients are receiving treatment several hours after symptom onset in most cases, which leads to worse outcomes.

Further, for each observation hospital in our dataset, we identified another hospital as a competitor if that hospital is within a sixty minute drive from the centroid of the observation hospital's zip code. However, as all nearby hospitals contribute to a weighted mean which also uses current admissions as a measure of size, small variations in measured distance from a focal hospital have minimal influence on measured adoption rates; that is, the weighted mean is very robust to small errors in measurement of distance.

Thus, there are measures of (1) the population that lives in the market area of each hospital, and characteristics of that population, (2) the fraction of that population that is within an hour of another hospital providing the relevant cardiac service, and (3) nearby hospitals' service offerings. Note that when a nearby hospital adds a new service, it has two effects: some nearby zip codes may newly have access to cardiac care (there is a drop in the population counted as having no access), but the fraction of nearby hospitals offering the service jumps at other nearby hospitals which are at risk of adding the service. These two changes are correlated but very imperfectly, both due to the sizes of affected areas and differences in the weighting (population weights across all nearby zip codes, or admission weights across all nearby hospitals). With these two imperfectly correlated variables used as separate predictors, we expect the standard errors to be larger but to the extent that effects are large enough to be detectable, there is no bias introduced by modest collinearity. 


\section{Empirical Specification}

In our main specifications, we investigate the extent to which the probability that each hospital adopts a new service (alternately diagnostic services, PCI, and CABG) in a given year depends upon (1) the percentage of patients in the market that already have access to these services in the current year, and (2) the percentage of competing hospitals in the market that also adopt a service that same year. More specifically, we fit a discrete-time hazard model to annual data, assuming that the hazard of adoption (conditional probability of adoption of a given technology by the hospital, given no adoption to date) is proportional to a common baseline hazard specified flexibly over time. The continuous time Proportional Hazard (PH) model is of the form $\log \left(\mathrm{H}_{\mathrm{it}} ; \mathrm{X}_{\mathrm{it}}\right)=\mathrm{f}(\mathrm{t})+\mathrm{X}_{\mathrm{it}} \mathrm{b}$ or $\mathrm{H}_{\mathrm{it}}=\exp \left(\mathrm{f}(\mathrm{t})+\mathrm{X}_{\mathrm{it}} \mathrm{b}\right)$, where $\mathrm{f}(\mathrm{t})$ is an arbitrary function of time. The interval-censored PH model is of the form $\operatorname{cog} \log \left(H_{i j} ; X_{i j}\right)=g(j)+X_{i j} b$, where $t$ is continuous time, $\mathrm{j}$ is an index for ordered intervals i.e. years, and $\mathrm{g}(\mathrm{j})$ is an arbitrary function estimated via year dummies. The cloglog regression for a discrete-time hazard model is fit via a generalized linear model

$$
h_{i j}=f\left(Z_{i j} a+X_{i j} b+T_{i j} g\right)+e_{i j}
$$

where the inverse cloglog function $f(x)=1-\exp (-\exp (x))$ and $\mathrm{j}$ indexes time to indicate that time is measured in discrete intervals. This model is similar to a logit for low-probability events (as is the case with the hazard of adoption in any given year), as demonstrated by the comparison of the inverse cloglog and inverse logit functions shown in Figure 1. Hazards of 5 percent are -2.94 on the logit curve and -2.97 on the cloglog curve; hazards of 3 percent are -3.48 on the logit curve and -3.49 on the cloglog curve. At the rate of 1 to 2 percent for the baseline hazard of adoption of cardiac services in our data, the cloglog and logit models are essentially indistinguishable. 
We use hazard models to estimate the risk of a hospital offering a new cardiac service, alternately diagnostic angiography, PCI, and CABG. Generally, hospitals that offer PCI also offer diagnostic angiography, and those that offer CABG also offer diagnostic angiography and PCI (fewer than 12 hospitals per year $(0.32 \%)$ offered a different mix of services). The primary independent variables measure the extent to which patients in each observation hospital's market already had access to that service and the rate by which the observation hospital's competitors adopted a new service. We estimate the following model:

(1) $\quad \mathrm{E}(\text { ServiceProvided })_{i t}=f\left[\beta_{\mathrm{o}}+\beta_{1} \mathrm{~N}_{\mathrm{it}}+\beta_{2} \mathrm{Y}_{\mathrm{t}}+\beta_{3} \mathrm{D}_{\mathrm{it}}+\beta_{4} \mathrm{H}_{\mathrm{it}}\right]$

where $\mathrm{N}$ are the primary independent variables of interest, including: (1) the percentage of the population in each observation hospital's market that already has access to the service in question in the current year; and (2) the rate at which an observation hospital's competitors, defined as all hospitals that also lie within 60 minutes driving time of the observation hospital, adopt the service in question during the same year. The percentage of the population in each hospital's market that already has access to a service at a hospital they are likely to visit was determined by examining zip code tabulation areas within an hour's drive. For each of these nearby zip codes, we calculate whether hospitals (other than the observation hospital) within a maximum of sixty minutes of the centroid of that ZCTA offered the service, then computed the weighted average of that indicator by hospital size and distance to get the zip-code probability of coverage. We then averaged those zip-code probabilities of coverage, across all zip codes within an hour of the hospital in question, weighting by population size and distance, to get the percentage of the nearby population likely to already have access. The rate at which an observation hospital's competitors adopted the service is an average of nearly hospitals' indicators, weighted by hospital size and distance. $\mathrm{D}$ is a vector of demographic variables for the 
hospital's patient market, again defined as all residents of ZCTAs, the centroids of which lie a maximum of sixty minutes driving time to the centroid of a ZCTA. The demographic variables are weighted by the size of the ZCTA's population and driving time from the observation hospital to the centroid of the ZCTA. We include these measures to account for differences by demographic status in the demand for invasive cardiac procedures. For example, men, especially older men, are more likely than women to suffer from cardiovascular disease (Cutler and Kadiyala, 2003). Education, income, race (being white), and age are all positively correlated with having health insurance (Smith and Medalia, 2015) and, therefore, variation in these attributes likely is correlated with geographic differences in the demand for (or profitability of) services. For similar reasons, we include variables measuring population size, age and sex (by percentage of the population in the market that is male or female and under 18, between 18 and 44, between 45 and 54, between 55 and 64, and equal to or older than 75), education (percentage of the population in the market with a high school degree or GED, some college, a college degree, with a graduate degree), percent income $\geq 100 \mathrm{~K}$, the percentage of people on public assistance, and race (white, black, and other - which included native American, Asian \& Pacific Islander, or mixed race; Hispanic).

Finally, we also measure whether the hospital is in an urban market, meaning the population density is at least 500 people per square mile. According to the criteria published in the Federal Register on March 15, 2002 (67 FR 11663), an "urbanized area" consists of densely settled territory that contains 50,000 or more people, with the "densely settled" criterion referring to at least 500 residents per square mile. This last variable, an indicator of density of the population, also effectively adjusts for regional differences in the patient population's willingness to drive longer distances. 
$\mathrm{H}$ is a vector of hospital and hospital market variables, including the size of the hospital measured by quintile of annual admissions, whether the hospital is a teaching hospital (measured by membership in either of two nonprofit organizations for teaching hospitals) and whether the hospital is part of a hospital network.

We also measure each observation hospital's Herfindahl-Hirschman index (HHI) to account for the concentration of hospitals in each hospital's observation market, defined as the sum of squared admission shares over all hospitals within sixty minutes driving time, unweighted by distance.

$\mathrm{Y}$ is a dummy variable for each year of data, to account for the baseline hazard of adoption in the most flexible nonparametric manner possible.

All standard errors (SE) are clustered at the hospital level. This clustering represents a conservative approach as to the nature of serial correlation within hospital, as the Maximum Likelihood Estimator of the discrete-time hazard model does not require a cluster-robust SE to account for multiple observations per unit of observation, but the cluster-robust SE is robust to any form of serial correlation.

We then estimate models of the form:

$$
\mathrm{E}(\text { ServiceProvided })_{\mathrm{it}}=\mathrm{f}\left[\beta_{\mathrm{o}}+\beta_{1} \mathrm{~N}_{\mathrm{it}}+\beta_{2} \mathrm{Y}_{\mathrm{t}}+\beta_{3} \mathrm{D}_{\mathrm{it}}+\beta_{4} \mathrm{H}_{\mathrm{it}}+\beta_{5} \mathrm{O}_{\mathrm{it}}\right]
$$

Equation (2) is the same as equation (1) with the addition of a vector of variables $\mathrm{O}$ which includes indicator variables for nonprofit, for-profit, or government ownership of the observation hospital. We also interact ownership variables with the variable measuring the adoption rate of competitor hospitals in the observation hospital's market.

To investigate the influence of market penetration by organizational form, we estimate models of the form: 
(3) $\mathrm{E}(\text { ServiceProvided })_{i t}=\mathrm{f}\left[\beta_{\mathrm{o}}+\beta_{1} \mathrm{~N}_{\mathrm{it}}+\beta_{2} \mathrm{Y}_{\mathrm{t}}+\beta_{3} \mathrm{D}_{\mathrm{it}}+\beta_{4} \mathrm{H}_{\mathrm{it}}+\beta_{5} \mathrm{O}_{\mathrm{it}}+\beta_{6} \mathrm{M}_{\mathrm{it}}\right]$

Equation (3) is the same as equation (2) with the addition of $\mathrm{M}$, a variable measuring the penetration of for-profit ownership in each market. The variable is an indicator variable representing whether more than 10 percent of the hospitals in a market have for-profit ownership (the median for-profit penetration across all markets and years is 6 percent, increasing from 5 to 7 percent between 1996 and 2014, and the mean is 13 percent, ranging from 12 in 1996 to 15 in 2014).The for-profit penetration variable is constructed as the average of a for-profit indicator over all hospitals within an hour drive of each zip code, weighted by distance, then weighted by population in that zip code and distance to the focal hospital. That is, market penetration is defined analogously to coverage in the population.

We also include interaction terms for the variable measuring high for-profit markets with the ownership of the observation hospitals and with the variable measuring the rate at which an observation hospital's competitors adopts each service:

(4) $\mathrm{E}(\text { ServiceProvided })_{i t}=\mathrm{f}\left[\beta_{\mathrm{o}}+\beta_{1} \mathrm{~N}_{\mathrm{it}}+\beta_{2} \mathrm{Y}_{\mathrm{t}}+\beta_{3} \mathrm{D}_{\mathrm{it}}+\beta_{4} \mathrm{H}_{\mathrm{it}}+\beta_{5} \mathrm{O}_{\mathrm{it}}+\beta_{6} \mathrm{M}_{\mathrm{it}}+\beta_{7} \mathrm{M}_{\mathrm{it}} \mathrm{O}_{\mathrm{it}}+\right.$ $\left.\beta_{8} \mathrm{M}_{\mathrm{it}} \mathrm{N}_{\mathrm{it}}\right]$

\section{Results and Limitations}

\subsection{Unadjusted Results.}

From 1997 to 2014, the proportion of hospitals offering invasive cardiac services grew over the study period (Table 1a). As can be seen in Table 1a, column 1, the proportion of hospitals not offering any invasive cardiac service declined; as can be seen in the remaining columns, a lower proportion of hospitals offered only diagnostic angiography over the study 
period (column 2) and higher percentage offered diagnostic and treatment services (columns $3 \&$ 4).

The rate of new service adoption by hospitals varied by year and by service type, although the proportion of hospitals newly adopting any of the services declined over the study period (Table 1b), as the fraction that had not yet adopted fell. The percentage of hospitals that adopted diagnostic angiography in a year fell from 1997 to 2014 , from 5.7 percent to 0.9 percent of hospitals that did not offer the service in the previous year (Table 1b, Column1). The percentage of hospitals that adopted PCI fell from 2.0 percent to 1.1 percent of hospitals that did not previously offer PCI in the previous year (Table 1b, Column 2). The percentage of hospitals that adopted CABG fell from 1.8 percent to 0.3 percent of hospitals that did not previously offer CABG (Table 1b, Column 3). Descriptive statistics for all variables are reported in Table 2 for the samples at risk of adoption (including all years in the risk pool). That is, the samples differ across columns in Table $1 \mathrm{~b}$ because the numbers of hospitals yet to adopt a service differ across service types. Still, we can see that adoption rates are roughly comparable comparing across columns.

Note that even relatively low adoption rates in one year imply large gains over time in offering rates. One and half percent of the risk pool adopting in each year (a 1.5 percent constant hazard) aggregated over 18 years would imply nearly a quarter of the hospitals not offering a service in the first year offer it by the last. Likewise, a small change in adoption rates can produce large changes over time, as hazard rates compound. For this reason, we compute changes in the expected rate of adoption and compare to baseline adoption rates.

5.2. Service Adoption, Geographic Access to Care, and Competitor Behavior. 
The probability of an observation hospital adopting a new service depends upon competition through two paths. First, it depends on the degree to which the observation hospital's potential patient pool has access to services at another hospital. The potential patients are the residents of ZCTAs the centroids of which fall a maximum of 60 minutes driving time from the observation hospital and whether they have access at another hospital is determined by whether the centroids of the ZCTAs in which they reside are within 60 minutes of another hospital offering that service. For economy of expression, we describe this variable as the hospital's market population already having access to care. Second, it depends on the degree to which an observation hospital's competitors also adopt the service in a given year. These two effects operate in different directions.

Controlling only for the year and demographic and hospital factors listed above, hospitals generally are more likely to adopt a new service if the populations in their markets already have access to that service at another hospital (Table 3, columns 1, 4, and 7, coefficients on the percent of the population with access to each service). To interpret the magnitude of the effects, we calculated the effect of a 10 percent increase in the percent of each hospital's market population who resided in a ZCTA the centroid of which is a maximum of sixty minutes driving time from another hospital offering the service in question. More specifically, we add coefficients to the transformed ${ }^{1}$ baseline hazard in the sample, then retransform to recover an estimated effect on the hazard for only that coefficient.

The probability of hospitals adding diagnostic angioplasty increases by approximately 0.09 percentage points or slightly over a 4 percent increase in the probability that a hospital

\footnotetext{
${ }^{1}$ The cloglog transformation of baseline hazard $h$ is $-\ln [\ln (1-h)]$, whereas the logit transformation is the $\log$ odds $\ln [(h) /(1-h)]$. If we add a coefficient $c$ to the transformed hazard to get $\mathrm{y}=c-\ln [\ln (1-h)]$, we retransform via 1 $\exp [-\exp (y)]$ for the new estimated hazard.
} 
newly adopts diagnostic angioplasty that year (the mean adoption rate in the sample is 2.38 percent per year). The corresponding percentages for PCI are considerably higher -0.63 percentage points or a 29.0 percent increase over a base rate of 2.16 percent per year in the sample. For $\mathrm{CABG}$ the numbers fall in the middle -0.10 percentage points or about a 10.7 percent increase over a base adoption rate of 0.964 percent per year in the sample. However, only the results for PCI differ statistically from zero.

As can be seen in Table 3 in the coefficients on the adoption rates of competitors for each service (column 2, 5, 8), hospitals are also quite responsive to the behavior of their competitors in terms of adopting new services. Hospitals are more likely to adopt a new service if their competitors also adopt the service in a given year. The magnitudes of these effects are very large and the coefficients for all three services are significant at the 1 percent level. The magnitude of the probability of a hospital adding diagnostic angioplasty increases by approximately 3.0 percentage points or about a 127 percent increase in the probability that a hospital newly adopts diagnostic angioplasty that year (the mean adoption rate is 2.39 percent). The corresponding percentages for PCI and CABG are even higher: for PCI, an increase of 2.83 percentage points, or a 133.1 percent increase over a base rate of 2.13 percent; for $\mathrm{CABG}, 1.79$ percentage points or about a 185 percent increase over a base adoption rate of 0.967 percent.

The two effects operate in opposite directs. Including both measures of percentage of residents in a hospital's market area with access to care at competing hospitals and the adoption behavior of competitors is perhaps most telling. As can be seen in Table 3, columns 3, 6, and 9, when the adoption rate of competitors is included in the model, the coefficients on the percentage of the population with access to each service is large, negative, and significant at the 1 percent level. Hospitals are deterred from offering a new service if the market population already has 
access to that service elsewhere. However, the coefficients on adoption rates for each service by competitors of each observation hospital is larger, in regressions adjusting for the percentage of the population with access elsewhere, than in regressions that do not control for that variable. These coefficients are also statistically significant at the one percent level.

Estimating the magnitude of these effects together is somewhat complicated because an increase in the number of competitor hospitals adopting a new service will also increase the percentage of the population that has geographic access to that service at another hospital. Nonetheless, to give a sense of the magnitude of the joint effect, we considered the case of a fifty percent increase in the number of competitors offering a new service. We assumed for the purposes of the simulation that this increase led to a twenty percent increase in the population with geographic access to the service, using the observed correlations of adoption and change in population coverage in our sample. ${ }^{2}$ Applying these assumptions, the probability of adopting cardiac angioplasty increases from 2.39 percent to 60.4 percent, for PCI from 2.13 percent to 51.3 percent, and for $\mathrm{CABG}$ from 0.97 percent to 81 percent.

\subsection{Hospital Ownership and Effects of Ownership Mix in Hospital Markets}

Consistent with previous research (Horwitz and Nichols, 2009), for-profit hospitals are more likely than nonprofit hospitals, which in turn are more likely than government hospitals, to adopt each of these three relatively profitable cardiac services and the coefficients on ownership of the observation hospital are all statistically significant at the one percent level (Table 4, rows 1

\footnotetext{
${ }^{2}$ These are large changes in market structure, but not infeasible, as such large changes are observed in only one to 5 percent of cases in our data, but a typical positive adoption rate is 20 percent (median for diagnostic angiography, with a 30 percent mean; 13 percent median and 19 percent mean for PCI; and 9 percent median and 15 percent mean for $\mathrm{CABG})$.
} 
and 2). Moreover, the magnitude of the effect of ownership of the observation hospital on the probability of adopting a new service is large.

Based on the coefficients reported in Table 4, column 1, for-profit hospitals are 2.02 percentage points more likely to adopt diagnostic angiography than are nonprofit hospitals; this represents an 84.3 percent increase in the probability of adoption on a base of 2.39 percent. The corresponding magnitudes for PCI are a difference of 1.32 percentage points, for an increase of 62.1 percent increase in the probability of adoption on a base of 2.13 percent, comparing forprofit hospitals to nonprofits. For CABG, the difference is 0.85 percentage points, or an 88.3 percent increased hazard, on a base of 0.97 percent.

Government hospitals are less likely to adopt new services than are nonprofit hospitals. Government hospitals are 0.97 percentage points less likely to adopt diagnostic angiography than are nonprofit hospitals; this represents a 40.1 percent decrease in the probability of adoption on a base of 2.39 percent. The corresponding magnitudes for PCI are -0.84 percentage points,point differential, for a decrease of 39.6 percent in the probability of adoption on a base of 2.13 percent. For $\mathrm{CABG}$, -the difference is 0.58 percentage points, or 60.1 percent decrease on a base of 0.97 percent.

Table 5 reports the probability of a hospital adopting a new service taking into account the penetration of for-profit hospitals in the market. When controlling for ownership of observation hospitals, the coefficients on the variable measuring high for-profit market penetration are negative, but only the coefficients on CABG are statistically significant. (Table 5, row 3).

Table 6 reports the results of interactions between an indicator variable for high for-profit penetration markets and 1) the ownership of observation hospitals, and 2) the adoption rate of 
their competitors. The results are consistent with previous research demonstrating nonprofit hospitals are more likely to adopt profitable cardiac services in markets with high for-profit penetration than in markets with fewer for-profits (Horwitz and Nichols, 2009), effectively behaving more like for-profits in markets with more for-profit competitors.

The interactions between hospital ownership and the adoption rates of competitors (FP/ Gov * Comp. adopting DxAngio/PCI/CABG), adjusting for the ownership of observation hospitals and high for-profit penetration in their markets, yields inconclusive results (Table 6). The only consistently statistically significant results suggest that for profit hospitals are more likely than nonprofit hospitals to increase the sophistication of their cardiac services as their competitors start offering invasive cardiac services in the form of diagnostic angiography. ${ }^{3}$ This can be seen in columns 3 and 4 (FP*Comp. adopting dxAngio). For-profit hospitals are 4.6 percentage points more likely than nonprofits to adopt PCI if their competitors adopt diagnostic angiography; this represents a 216 percent increase in the probability of adoption on a base of 2.13 percent. The magnitude of the effect increases when adjusting for the interaction between the adoption rates of competitors and being in a high for-profit market.

\subsection{Limitations}

There are several limitations to our study. First, there may be some measurement error in the service adoption variables. We identify hospitals as offering a service based on whether a hospital bills (or has billed) for eleven or more procedures on Medicare fee-for-service beneficiaries. It is possible that a hospital newly offers a service in a given year and provides fewer than eleven procedures or provides more procedures on patients who are not insured under

\footnotetext{
${ }^{3}$ Compared to nonprofit hospitals, for profit hospitals are less likely to adopt CABG if their competitors do (column 8; fp*adoption rate of competitors-CABG), but this is no longer statistically significant after adjusting for being in a for profit market (column 9).
} 
the Medicare fee-for-service program. However, patients who receive the services studied here tend to be old enough to qualify for Medicare. Medicare was the primary expected payer for 51.1 percent of hospital stays involving a cardiac stent insertion procedure in 2009 (Auerbach et. al., 2012). Over sixty percent of CABG patients are 65 or older (Epstein et. al., 2011; Table 2) and therefore are old enough to qualify for Medicare. Younger cardiac patients may also be covered by Medicare. In fact, in 2012, approximately seventeen percent of Medicare beneficiaries who were under 65 had Ischemic Heart Disease (CMS, 2015).

Nonetheless, hospitals may perform these services on patients insured under the Medicare Advantage program instead of, or in addition to, those covered by Medicare fee-forservice. However, even those regions with the highest levels of Medicare Advantage enrollment also have high levels of fee-for-service enrollment. At the end of the study period, in 2014, thirty percent of Medicare beneficiaries were enrolled in Medicare advantage plans, and by 2016 the rate was at least forty percent in five states (Jacobson, 2016). Therefore, even in these high enrollment states, sixty percent of all enrollees were in fee-for-service plans.

Second, as with any study using observational data, it is not possible to completely rule out bias due to endogeneity. Our results are consistent with hospitals simultaneously adopting new services in response to changes in an unobserved common factor driving up the demand for cardiac services in their markets, rather than in reaction to each other's decisions. However, because government reimbursement through Medicare payments accounts for the bulk of cardiac spending, it is unlikely that differences in market prices account for the differences in technology diffusion we find here. Moreover, our inclusion of extensive demographic and hospital control variables - most importantly, variables that control for population growth and 
changes in the age distribution in the markets - suggest that simultaneous response to demand shocks does not explain our results.

Following Oster (2017), as an additional robustness test we exclude groups of controls, alternately excluding: (1) education and income covariates and (2) race covariates, and rerun all the analyses described above. The coefficients and proportions of variance explained remain stable across analyses, with the coefficients in these alternate specifications remaining within the range of a single standard deviation of the specifications reported here (i.e. within one standard error). This exercise supports the notion that results are robust to the inclusion of multiple varieties of control variables. Nonetheless, it is possible that we have not measured, yet hospitals observe, changes in the population of a hospital's geographic market or other local shocks explain the results we have found. For example, if the adoption of catheterization labs is promoted by a third party (such as a stent manufacturer) in an area, or a conference is held in the area that promotes such adoption, all hospitals would be exposed to a common shock. In this case, adoptions could be correlated for that reason and not because hospitals are competing against each other. Even if that type of hypothetical common shock were the cause, however, the pattern of adoption we document is of direct policy concern, since it results in duplicative services more than increased access, and can lower welfare relative to a situation where some adoptions of new services are moved from a service-rich area to a service-poor area.

Third, it may be that hospitals simultaneously adopted new services, not in response to information that a competitor hospital planned to adopt, but rather in response to changes in the costs of supplying the service such as a decrease in input prices of the equipment or the physicians. It is unlikely that such decreases explain the patterns we observe. Over the study period, the percentage and number of hospitals adopting a new service decreased. And the patterns of adoption were clustered within markets as defined in this analysis (relatively small 
areas based on 60 minute driving distances) and were not consistent across the country, whereas markets for technology or talent are much larger if not national.

\section{Discussion}

Between 1996 and 2014, hospitals have continued to adopt new invasive cardiac services, although the rate of adoption slowed over the study period. Larger hospitals are more likely to adopt new services than are smaller hospitals. For-profit hospitals are more likely to adopt new services than are nonprofit hospitals, which, in turn, are more likely than government hospitals to adopt new services. On average, hospitals appear to make decisions regarding the adoption of new services based on the behavior of competitors in the markets in which they operate, controlling for population size and other characteristics.

The welfare effects of our findings regarding cardiac technology diffusion are uncertain. Although the spread of technology is generally good for social welfare, this has not always been the case with health care technology. Large geographic differences in the provision of care and in spending on care cannot be explained by differences in the population treated and have not led to differences in health outcomes, suggesting that there is a great deal of waste. Cardiac treatments are typically quite profitable services for hospitals (Horwitz, 2005), and oversupply is a particular worry for the provision of services that tend to be profitable for providers. In fact, at the extreme, there have been distressing cases of hospitals and physician providing services, particularly profitable services such as cardiac treatments, to patients who did not need the intervention (Eisler and Hansen, 2013; Vrana and White, 2003).

Although our study does not measure social welfare directly, the results suggest that current patterns of cardiac technology diffusion can either increase or decrease social welfare, depending on conditions of a health care market. Social welfare is enhanced if hospitals base 
their decisions to adopt on the existence of unmet medical need in their markets. And, there is some evidence that they are doing so. They are less likely to adopt a new service if the patients in their markets already have geographic access to a service at another hospital.

However, previous research finding little increase in geographic access to care suggests that adoption decisions are in fact driven by a competitor's decision to adopt (Horwitz et al. 2013). Our results strongly support this finding. Although hospitals respond to the needs of potential patients to be within sixty minutes driving time of an invasive cardiac service, they also respond to the behavior of their competitors and adopt even if doing so duplicates existing services, failing to increase geographic access.

Nonetheless, even if competition has led to inefficient diffusion, there may well be offsetting benefits to hospital competition. Recent studies have identified benefits to hospital competition in terms of reducing excess capacity (Santerre and Adams, 2002), prices (Town and Vistnes, 2001), and adverse outcomes (Kessler and McClellan, 2000). The link between hospitallevel volume and improved patient outcomes implies such effects are unlikely for the cardiac services in this study, but such effects are outside the scope of this study. Future research should investigate the relationship among adoption, the role of hospital competition for patients and services, and outcomes such as health status and spending.

In addition to identifying two mechanisms that may explain a hospital's decision to adopt a new service, we find that for-profit hospitals are considerably more likely than nonprofits to adopt new services. However, this study does not find many differences in the relationship between ownership and responsiveness to the adoption decisions of competitors.

Despite improvements in treatments, cardiovascular disease is the leading cause of death in the United States and has been for many decades, though whether cancer or cardiovascular 
disease is the leading cause has recently begun to vary by race and socioeconomic status (Heron and Anderson, 2016). Understanding the continued diffusion of treatments in markets that already have geographic access may help in addressing this persistent health problem. 


\section{References}

Aghion, P., Bechtold S., Cassar, L., \& Herz, H. (2014). The causal effects of competition on innovation: experimental Evidence. NBER Working Paper 19987.

Auerbach, D., Maeda, J.L., \& Steiner, C. (2012). Hospital stays with cardiac stents, 2009. HCUP Statistical Brief \#128. Retrieved February 14, 2017, from http://www.hcupus.ahrq.gov/reports/statbriefs/sb128.pdf

Bates, E.R. \& Jacobs, A.K. (2013). Time to treatment in patients with STEMI. New England Journal of Medicine, 369(10), 889-892.

Boden, W.E. (2012). Mounting evidence for lack of PCI benefit in stable ischemic heart disease: what more will it take to turn the tide of treatment? Archives of Internal Medicine, 172(4), 319-321.

Boersma, E., Maas, A.C.P., Deckers J.W., \& Simoons, M.L. (1996). Early thrombolytic treatment in acute myocardial infarction: reappraisal of the golden hour. The Lancet, 348, $771-775$.

Bradley, E.H., Curry, L.A., Webster, T. R., Mattera, J.A., Roumanis, S.A., Radford, M. J., McNamara, R.L., Barton, B.A., Berg, D.N., \& Krumholz, H. M. (2006). Achieving rapid door-to-balloon times how top hospitals improve complex clinical systems. Circulation, 113, 1079-1085.

Center for Evaluative Clinical Sciences. (2005). The Dartmouth Atlas of HealthCare: Studies of Surgical Variation, Cardiac Surgery Report.

Center for Medicare \& Medicaid Services. (July 2015). Health Disparities in the Medicare Population. https://www.cms.gov/About-CMS/Agency- 
Information/OMH/Downloads/OMH_Dwnld-DataSnashot-Ischemic-HeartDisease_Final_082015-508.pdf

Chandra, A. \& Skinner, J.S. Technology growth and expenditure growth in health care. Journal of Economic Literature 2012, 50(3), 645-680.

Chen, J., Krumholz, H.M., Wang, Y. Curtis, J.P., Rathore, S.S., Ross, J.S., Normand, S.T., Schreiner, G.C., Mulvey, G., \&Nallamothu, B.K. (2010). Differences in patient survival after acute myocardial infarction by hospital capability of performing percutaneous coronary intervention. Archives of Internal Medicine, 170(5), 433-439.

Concannon, T.W., Nelson, J., Goetz, J., \& Griffith, J.L. (2012). A percutaneous coronary intervention lab in every hospital? Circulation: Cardiovascular Quality and Outcome, 5(1), 14-20.

Cutler, D.M. (2004). Your Money or Your Life. Oxford University Press.

Cutler, D.M. \& Kadiyala, S. (2003). “The return to biomedical research: treatment and behavioral effects.” In K. M. Murphy \& R.H. Topel (Eds.), Measuring the gains from medical research: an economic approach (pp.110-62). The University of Chicago Press.

Cutler, D.M. \& McClellan, M. (2001). Is technological change in medicine worth it? Health Affairs, 20(5), 11-29.

Doyle, J.J., Graves, J., Gruber, J., \& Kleiner, S. (2015). Measuring returns to hospital care: evidence from ambulance referral patterns. Journal of Political Economy, 123(1), 170214.

Eisler, P. \& Hansen, B. (2003). Doctors perform thousands of unnecessary surgeries. USA Today. Retrieved February 14, 2017, from 
http://www.usatoday.com/story/news/nation/2013/06/18/unnecessary-surgery-usa-todayinvestigation/2435009/

Epstein, A.J., Polsky, D., Yang F., Yang, L., \& Groeneveld, P.W. (2011). Coronary revascularization trends in the United States, 2001-2008. Journal of the American Medical Association, 305(17), 1769-1776.

Finks, J.F., Osbourne, N.H., \& Birkmeyer, J.D. (2011). Trends in hospital volume and operative mortality for high-risk surgery. New England Journal of Medicine, 364(22), 2128-37.

Flynn, A., Moscucci, M., Share, D., Smith, D., LaLonde, T., Changezi, H., Riba, A., \& Gurm, H.S. (2010). Trends in door-to-balloon time and mortality in patients with ST-elevation myocardial infarction undergoing primary percutaneous coronary intervention. Archive Internal Medicine, 170(20), 1842-9.

Heidenreich, P.A., Trogdon, J.G., Khavjou, O. A., Butler, J., Dracup, K., Ezekowitz, M.D., Finkelstein, E.A., Hong, Y., Johnston, S. C., Khera, A., Lloyd-Jones, D. M., Nelson, S. A., Nichol, G., Orenstein, D., Wilson, P. W.F., \& Woo, Y.J. (2011). Forecasting the future of cardiovascular disease in the United States: a policy statement from the American Heart Association. Circulation, 123, 933-944.

Heron, M. \& Anderson, R.N. (2016). Changes in the leading cause of death: recent patterns in heart disease and Cancer Mortality. NCHS Data Brief No. 254. Retrieved February 14, 2017, from https://www.cdc.gov/nchs/data/databriefs/db254.pdf

Hillman, B.D., Neu, C.R., Winkler, J.D., Aroesty, J., Rettig, R.A., \& Williams, A.P. (1987). The diffusion of magnetic resonance imaging scanners in a changing U.S. health care environment. International Journal of Technology Assessment in Health Care, 3(4), 545559. 
Ho, V. (2002). Learning and the evolution of medical technologies: the diffusion of coronary angioplasty. Journal of Health Economics, 21(5), 873-885.

Horwitz, J.R. (2005). Making profits and providing care: comparing nonprofit, for-profit, and government hospitals. Health Affairs, 24(3), 790-801

Horwitz, J.R. \& Nichols, A. (2009). Hospital ownership and medical services: market mix, spillover effects, and nonprofit objectives. Journal of Health Economics, 28, 924-937.

Horwitz, J.R, Nichols, A., Nallamothu, B.K., Sasson, C., \& Iwashyna, T.J. (2013). Expansion of invasive cardiac services in the United States. Circulation, 128(8), 803-10.

Howard, D.H. \& Shen Y. (2014). Trends in PCI volume after negative results from the COURAGE trial. Health Services Research, 49(1), 153-170.

Jacobson, G., Casillas, G., Damico, A., Neuman, T. \& Gold, M. (2016). Medicare advantage 2016 spotlight: enrollment market update. Retrieved February 14, 2017, from http://files.kff.org/attachment/Issue-Brief-Medicare-Advantage-2016-SpotlightEnrollment-Market-Update

Kessler, D. P., \& McClellan, M.B. (2000). Is hospital competition socially wasteful? The Quarterly Journal of Economics, 115(2), 577-615.

Ladapo, J.A., Horwitz, J.R., Weinstein, M.C., Gazelle, G.S., \& Cutler, D.M. (2009). Adoption and spread of new imaging technology: a case study. Health Affairs, 28(6), w1122-w32.

Lange, R.A., \& Hillis, L.D. (2003). Diagnostic cardiac catheterization. Circulation, 107, e111e113.

Levine, G.N., Bates, E.R., Blankenship, J.C., Bailey, S.R., Bittl, J.A., Cercek, B., Chambers, C.E., Ellis, S.G., Guyton, R.A., Hollenberg, S.M., Khot, U.N., Lange, R.A., Mauri, L., Mehran, R., Moussa, I.D., Mukherjee, D., Nallamothu, B.K., Ting, B.H. (2011). 2011 
ACCF/AHA/SCAI guideline for percutaneous coronary intervention. Circulation, 124, e547-e651.

Matlock, D.D., Groeneveld, P.W., Sidney, S., Shetterly, S., Goodrich, G., Glenn, K., Xu, S., Yang, L., Farmer, S.A., Reynolds, K., Cassidy-Bushrow, A.E., Lieu, T., Boudreau, D.M., Greenlee, R.T., Tom, J., Vupputuri, S., Adams, K.F., Smith, D.H., Gunter, M.J., Go, A.S., \& Magid, D.J. (2013). Geographic variation in cardiovascular procedures: Medicare fee-for-service vs. Medicare Advantage beneficiaries. Journal of the American Medical Association, 310(2):155-161. DOI 10.1001/jama.2013.7837.

Menees, D.S., Peterson, E.D., Wang, Y.W., Curtis, J.P., Messenger, J.C., Rumsfeld, \& Gurm, H.S. (2013). Door-to-balloon time and mortality among patients undergoing primary PCI. New England Journal of Medicine, 369(10), 901-09.

Nallamothu, B.K., Bates, E.R., Wang, Y., Bradley, E.H., \& Krumholz, H.M. (2006). Driving times and distances to hospitals with percutaneous coronary intervention in the United States. Circulation, 113, 1189-1195.

Oster, E. (forthcoming 2017). Unobservable selection and coefficient stability: theory and validation. Journal of Business Economics and Statistics.

Robinson, J., \& Luft, H. (1985). The impact of hospital market structure on patient volume, average length of stay, and the cost of care. Journal of Health Economics, 4, 333-56.

Ross, J.S., Normand, S.T., Wang, Y., Ko, D.T., Chen, J., Drye, E.E., Keenan, P.S., Lichtman, J.H., Bueno, H., Schreiner, G.C., \& Krumholz, H.M. (2010). Hospital volume and 30-day mortality for three common medical conditions. New England Journal of Medicine, 362, $1110-1118$. 
Santerre, R. E., \& Adams, A.S., (2002). The effect of competition on reserve capacity: the case of California hospitals in the late 1990s. International Journal of Healthcare Finance and Economics, 2, 205-18.

Shapiro, C. (2012). Competition and innovation: did Arrow hit the bull's eye? In J. Lerner \& S. Stern (Eds.), The rate $\&$ direction of inventive activity revisited (pp.361-410). The University of Chicago Press.

Skinner, J.S., Staiger, D.O. (2015). Technology diffusion and productivity growth in health care. Review of Economics and Statistics, 97(5), 951-964.

Skinner, J.S., Staiger D.O, \& Fisher, E.S. (2006). Is technological change in medicine always worth it? The case of acute myocardial infarction. Health Affairs, 25, w34-w47.

Smith, J.C. \& Medalia, C. (2015). Health insurance coverage in the United States: 2014, Current population reports. Retrieved February 14, 2017, from U.S. Department of Commerce, Economics and Statistics Administration Web site: https://www.census.gov/content/dam/Census/library/publications/2015/demo/p60253.pdf

Stergiopoulos, K. \& Brown, D.L. (2012). Initial coronary stent implantation with medical therapy vs medical therapy alone for stable coronary artery disease: meta-analysis of randomized controlled trials. Archives of Internal Medicine, 172(4), 312-319.

Stergiopoulos, K., Boden, W.E., Hartigan, P., Möbius-Winkler, S., Hambrecht, R., Hueb, W., Hardison, R.M., Abbott, J.D., \& Brown, D.L. (2014). Percutaneous coronary intervention outcomes in patients with stable obstructive coronary artery disease and myocardial ischemia: a collaborative meta-analysis of contemporary randomized clinical trials. Archives of Internal Medicine, 174(2), 232-40. 
Teplensky J.D., Pauly M.V., Kimberly J.R., Hillman A.L., \& Schwartz J.S. (1995). Hospital adoption of medical technology: an empirical test of alternative models. Health Services Research Journal, 30(3), 437-465.

Torio, C.M., \& Moore, B.J. (2016). National Inpatient Hospital Costs: The Most Expensive Conditions by Payer, 2013. HCUP Statistical Brief \#204. Retrieved February 14, 2017, from https://www.hcup-us.ahrq.gov/reports/statbriefs/sb204-Most-Expensive-HospitalConditions.pdf

Town, R. \& Vistnes, G. (2001). Hospital competition in HMO networks. Journal of Health Economics, 20(3), 313-24.

Vrana, D. \& R.D. White. (2003). Tenet to settle charges over cardiac care [Electronic version]. L.A. Times. Retrieved February 14, 2017, from http://articles.latimes.com/2003/aug/07/business/fi-settle7

Weisfeldt M.L. \& S.J. Zieman, S.J. (2007). Advances in the prevention and treatment of cardiovascular disease. Health Affairs, 35(12), 25-37.

Wennberg, D.E., Birkmeyer, J.D. \& Dartmouth Atlas of Cardiovascular Health Working Group. (1999). The Dartmouth Atlas of Cardiovascular Health Care. Chicago: AHA Press.

Wilson, C.T., Fisher, E.S., Welch, H.G., Siewers, A.E., \& Lucas, F.L. (2007). U.S. trends in CABG hospital volume: the effect of adding cardiac surgery programs. Health Affairs, 26(1), $162-168$ at 164. 
Figure 1. Comparison of cloglog and logit link functions for hazard

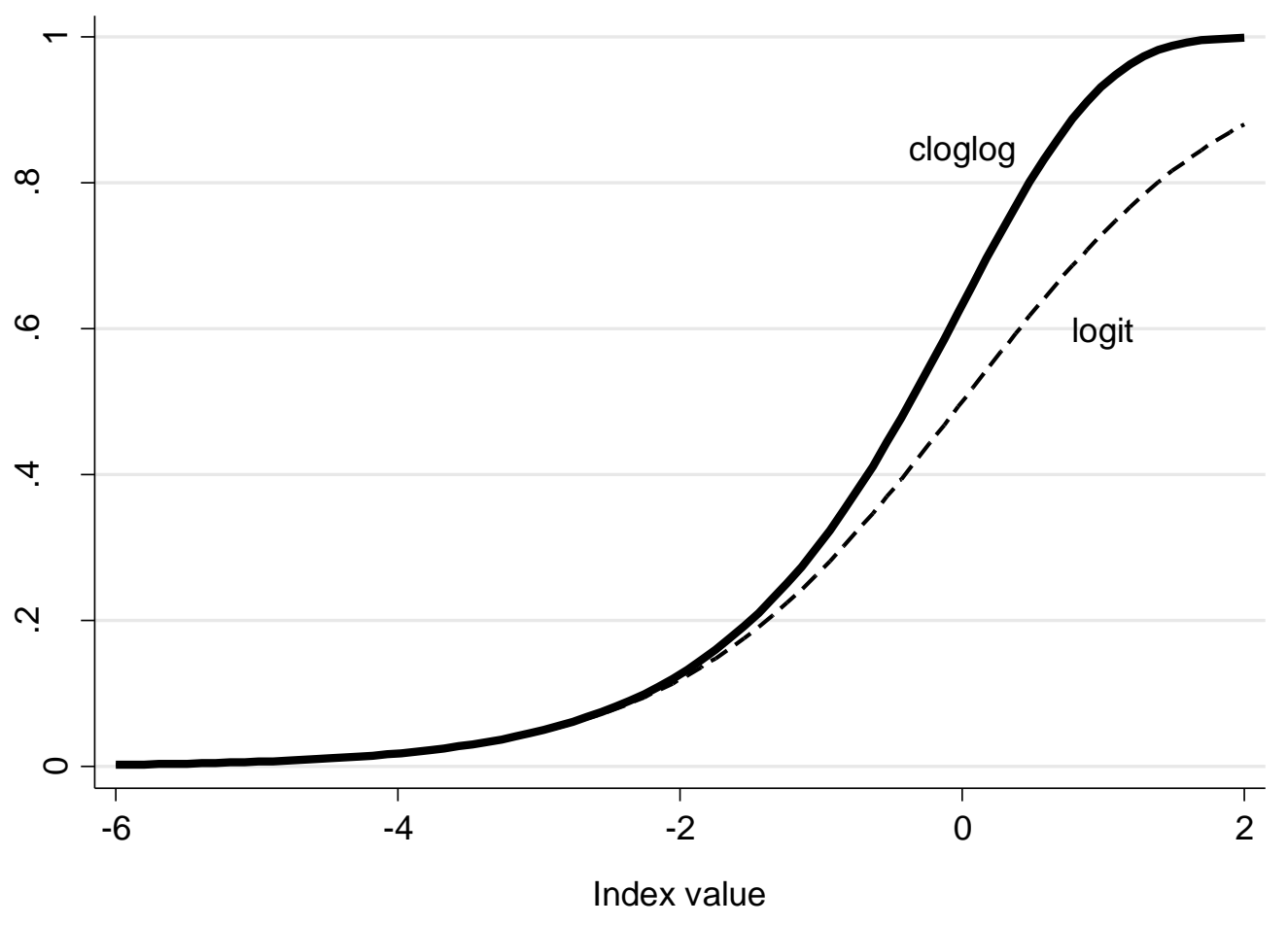


Table 1a. Proportion of Hospitals Offering Cardiac Services (1997-2004).

\begin{tabular}{|c|c|c|c|c|c|}
\hline Year & None & $\begin{array}{c}\text { Diagnostic } \\
\text { Angiography }\end{array}$ & $\begin{array}{c}\text { Diagnostic } \\
\text { Angiography \& } \\
\text { PCI }\end{array}$ & $\begin{array}{c}\text { Diagnostic } \\
\text { Angiography, } \\
\text { PCI \& CABG }\end{array}$ & $\begin{array}{c}\text { Total Number } \\
\text { of Hospitals }\end{array}$ \\
\hline 1997 & $(1)$ & $(2)$ & $(3)$ & $(4)$ & $(5)$ \\
\hline 1998 & 0.506 & 0.231 & 0.012 & 0.247 & 3,566 \\
\hline 1999 & 0.505 & 0.229 & 0.014 & 0.249 & 3,713 \\
\hline 2000 & 0.499 & 0.226 & 0.017 & 0.252 & 3,774 \\
\hline 2001 & 0.496 & 0.222 & 0.021 & 0.256 & 3,784 \\
\hline 2002 & 0.489 & 0.207 & 0.027 & 0.262 & 3,799 \\
\hline 2003 & 0.479 & 0.199 & 0.030 & 0.272 & 3,807 \\
\hline 2004 & 0.471 & 0.193 & 0.051 & 0.285 & 3,813 \\
\hline 2005 & 0.459 & 0.188 & 0.062 & 0.291 & 3,798 \\
\hline 2006 & 0.455 & 0.175 & 0.074 & 0.296 & 3,803 \\
\hline 2007 & 0.450 & 0.169 & 0.079 & 0.302 & 3,793 \\
\hline 2008 & 0.445 & 0.163 & 0.087 & 0.304 & 3,795 \\
\hline 2009 & 0.439 & 0.156 & 0.098 & 0.307 & 3,789 \\
\hline 2010 & 0.434 & 0.150 & 0.108 & 0.308 & 3,773 \\
\hline 2011 & 0.431 & 0.141 & 0.117 & 0.310 & 3,764 \\
\hline 2012 & 0.429 & 0.132 & 0.126 & 0.314 & 3,753 \\
\hline 2013 & 0.424 & 0.128 & 0.132 & 0.317 & 3,728 \\
\hline 2014 & 0.421 & 0.123 & 0.136 & 0.320 & 3,709 \\
\hline
\end{tabular}

Notes: Proportion offering a service is the fraction of hospitals treating cardiac patients that offered a service /total number of hospitals in the year. A hospital is treated as offering a service if it newly adopted a service in the observation year or any previous year in the sample. Columns 1-4 may not sum to one due to rounding and due to hospitals (fewer than 12 per year $(0.32 \%)$ ) offering a different mix of services, such as diagnostic angiography and CABG but not PCI, or PCI and CABG but not diagnostic angiography.

Source: Author calculations based on Medicare Provider Analysis and Review (MedPar) files for 100 percent of Medicare beneficiaries (1996-2014). 
Table 1b. Proportion of Hospitals Adopting Cardiac Services (1997-2014).

\begin{tabular}{|r|r|r|r|}
\hline Year & Diagnostic Angiography & PCI & CABG \\
\hline & $(1)$ & $(2)$ & 0.018 \\
\hline 1997 & 0.057 & 0.020 & 0.013 \\
\hline 1998 & 0.036 & 0.017 & 0.013 \\
\hline 2090 & 0.028 & 0.019 & 0.009 \\
\hline 2001 & 0.020 & 0.016 & 0.014 \\
\hline 2002 & 0.023 & 0.022 & 0.017 \\
\hline 2003 & 0.029 & 0.024 & 0.012 \\
\hline 2004 & 0.027 & 0.030 & 0.011 \\
\hline 2005 & 0.029 & 0.026 & 0.010 \\
\hline 2006 & 0.030 & 0.027 & 0.012 \\
\hline 2007 & 0.022 & 0.032 & 0.011 \\
\hline 2008 & 0.019 & 0.019 & 0.007 \\
\hline 2009 & 0.019 & 0.022 & 0.006 \\
\hline 2010 & 0.020 & 0.025 & 0.003 \\
\hline 2011 & 0.020 & 0.023 & 0.006 \\
\hline 2012 & 0.010 & 0.022 & 0.004 \\
\hline 2013 & 0.013 & 0.021 & 0.004 \\
\hline 2014 & 0.015 & 0.015 & 0.003 \\
\hline
\end{tabular}

Notes: Proportion adopting a service is the number of hospitals treating cardiac patients that newly adopted the service in that year divided by the number of hospitals that did not offer the service the previous year (the risk pool for adoption). A hospital may only adopt each service once. The denominator differs by service and only includes hospitals that were in both that year and the previous year (the risk pool must be observed in both years). For diagnostic angiography the denominator equals the number of hospitals that did not offer any service in the previous year. For PCI, the dominator equals the number of hospitals that did not offer PCI; the denominator for CABG is the number of hospitals that did not offer CABG the previous year. A hospital is considered not to have offered a service in a year if it has not previously adopted the service, not adopted the service in that year, and did not offer the service in the base year (1996).

Source. Author calculations based on Medicare Provider Analysis and Review (MedPar) files for 100 percent of Medicare beneficiaries (1996-2014). 
Table 2. Covariate means for hospitals that offer each service and their markets (1997).

\begin{tabular}{|c|c|c|c|}
\hline & $\begin{array}{c}\text { (1) } \\
\text { Dx Angiography }\end{array}$ & $\begin{array}{l}(2) \\
\text { PCI }\end{array}$ & $\begin{array}{c}(3) \\
\text { CABG }\end{array}$ \\
\hline For-profit hospital & 0.121 & 0.140 & 0.146 \\
\hline Nonprofit hospital & 0.596 & 0.617 & 0.619 \\
\hline Government hospital & 0.283 & 0.243 & 0.234 \\
\hline High-FP market (> 10\%) & 0.374 & 0.380 & 0.381 \\
\hline$\%$ pop w/ DxAngio access & 0.694 & 0.733 & 0.743 \\
\hline$\%$ pop w/PCI access & 0.541 & 0.566 & 0.582 \\
\hline$\%$ pop w/CABG access & 0.482 & 0.509 & 0.518 \\
\hline Adoption rate of competitors - DxAngio & 0.040 & 0.047 & 0.048 \\
\hline Adoption rate of competitors - PCI & 0.031 & 0.039 & 0.040 \\
\hline Adoption rate of competitors - CABG & 0.017 & 0.019 & 0.019 \\
\hline Smallest hospitals (lowest fifth admit) & 0.415 & 0.303 & 0.280 \\
\hline Small hospitals (20th -40 th percentile admit) & 0.351 & 0.291 & 0.275 \\
\hline Mid-size $\left(40^{\text {th }}-60\right.$ th percentile admit $)$ & 0.166 & 0.231 & 0.241 \\
\hline Medium-large $\left(60^{\text {th }}-80\right.$ th percentile admit $)$ & 0.054 & 0.131 & 0.150 \\
\hline Teaching hospital & 0.040 & 0.078 & 0.090 \\
\hline Herfindahl-Hirschman Index (Hosp $\leq 60 \mathrm{~min})$ & 0.249 & 0.220 & 0.214 \\
\hline Hospital is in a system & 0.475 & 0.512 & 0.523 \\
\hline Population density $\geq 500$ people/ sq mile & 0.248 & 0.342 & 0.366 \\
\hline ln Pop density & 5.455 & 5.759 & 5.833 \\
\hline Ln pop nearby & 9.740 & 9.847 & 9.876 \\
\hline$\%$ pop. male under 18 & 0.255 & 0.255 & 0.254 \\
\hline$\%$ pop. male $18-44$ & 0.377 & 0.381 & 0.381 \\
\hline$\%$ pop. male $45-54$ & 0.137 & 0.137 & 0.138 \\
\hline$\%$ pop. male $55-64$ & 0.106 & 0.104 & 0.105 \\
\hline$\%$ pop. male 75 plus & 0.053 & 0.052 & 0.051 \\
\hline$\%$ pop. female under 18 & 0.235 & 0.234 & 0.234 \\
\hline$\%$ pop. female $18-44$ & 0.357 & 0.361 & 0.362 \\
\hline$\%$ pop. female $45-54$ & 0.136 & 0.136 & 0.136 \\
\hline$\%$ pop. female $55-64$ & 0.108 & 0.107 & 0.108 \\
\hline$\%$ pop. female 75 plus & 0.083 & 0.081 & 0.080 \\
\hline$\%$ pop. high school graduate or GED & 0.322 & 0.315 & 0.313 \\
\hline$\%$ pop. some college & 0.211 & 0.209 & 0.209 \\
\hline$\%$ pop. college graduate & 0.209 & 0.213 & 0.216 \\
\hline$\%$ pop. with graduate degree & 0.076 & 0.081 & 0.083 \\
\hline$\%$ pop. Hispanic & 0.093 & 0.097 & 0.099 \\
\hline$\%$ pop. White & 0.814 & 0.798 & 0.794 \\
\hline$\%$ pop. Black & 0.101 & 0.113 & 0.116 \\
\hline$\%$ pop. Household income $\geq \$ 100 \mathrm{~K}$ & 0.100 & 0.105 & 0.109 \\
\hline$\%$ pop. Receiving public assist. & 0.110 & 0.109 & 0.110 \\
\hline Observations & 31,787 & 43,851 & 47,572 \\
\hline
\end{tabular}

Notes: \% pop with service access and \% pop with demographic characteristics are determined based on the percentage of the population in each hospital's market that is in a ZCTA with a centroid $\leq 60$ min driving distance to a hospital with the service or with the characteristic. Adoption rate of competitors $=$ distance and admission weighted percentage of competitors that adopt a service; hospital sizes based on annual admissions.

Sources: American Hospital Association's Annual Surveys of Hospitals (AHA) 1996-2014; U.S. Census (2000); American Community Survey (2010-2014); Medicare Provider Analysis and Review (MedPar) files for 100 percent of Medicare beneficiaries (1996-2014). 
Table 3. Probability of Adopting New Service: Existing Population Access and Adoption by Competitors, $1997-2004$.

\begin{tabular}{|c|c|c|c|c|c|c|c|c|c|}
\hline & (1) & (2) & (3) & (4) & (5) & (6) & (7) & (8) & (9) \\
\hline$\%$ pop w/ DxAngio access & $\begin{array}{l}\text { DxAngio } \\
0.408 \\
(0.389)\end{array}$ & DxAngio & $\begin{array}{l}\text { DxAngio } \\
-4.749^{* * *} \\
(0.533)\end{array}$ & $\begin{array}{l}\text { PCI } \\
-1.452^{* * *} \\
(0.418)\end{array}$ & PCI & $\begin{array}{l}\text { PCI } \\
0.340 \\
(0.449)\end{array}$ & $\begin{array}{c}\text { CABG } \\
-1.183^{*} \\
(0.535)\end{array}$ & CABG & $\begin{array}{l}\text { CABG } \\
0.119 \\
(0.713)\end{array}$ \\
\hline$\%$ pop w/PCI access & $\begin{array}{l}0.588 \\
(0.536)\end{array}$ & & $\begin{array}{l}-0.104 \\
(0.858)\end{array}$ & $\begin{array}{l}2.577^{* * * *} \\
(0.454)\end{array}$ & & $\begin{array}{l}-9.175^{* * * *} \\
(0.869)\end{array}$ & $\begin{array}{l}0.0489 \\
(0.785)\end{array}$ & & $\begin{array}{l}0.110 \\
(0.751)\end{array}$ \\
\hline$\%$ pop w/CABG access & $\begin{array}{l}-0.625 \\
(0.512)\end{array}$ & & $\begin{array}{l}2.925^{* * * *} \\
(0.855)\end{array}$ & $\begin{array}{l}-1.313^{* * *} \\
(0.332)\end{array}$ & & $\begin{array}{l}6.947^{* * * *} \\
(0.807)\end{array}$ & $\begin{array}{l}1.021 \\
(0.717)\end{array}$ & & $\begin{array}{l}-3.425^{* * * *} \\
(0.723)\end{array}$ \\
\hline Smallest (lowest fifth admit) & $\begin{array}{l}-5.324^{* * * *} \\
(0.288)\end{array}$ & $\begin{array}{l}-4.932^{* * * *} \\
(0.321)\end{array}$ & $\begin{array}{l}-4.721^{\text {**** }} \\
(0.330)\end{array}$ & $\begin{array}{l}-4.711^{* * * *} \\
(0.284)\end{array}$ & $\begin{array}{l}-4.909^{* * * *} \\
(0.317)\end{array}$ & $\begin{array}{l}-4.589^{* * * * *} \\
(0.334)\end{array}$ & $\begin{array}{l}-4.573^{* * * *} \\
(0.364)\end{array}$ & $\begin{array}{l}-4.480^{* * * *} \\
(0.405)\end{array}$ & $\begin{array}{l}-4.166^{* * * *} \\
(0.412)\end{array}$ \\
\hline Small (20-40th \%ile admit) & $\begin{array}{l}-3.681^{\text {**** }} \\
(0.217)\end{array}$ & $\begin{array}{l}-3.208^{* * * *} \\
(0.237)\end{array}$ & $\begin{array}{l}-3.046^{* * * *} \\
(0.238)\end{array}$ & $\begin{array}{l}-3.352^{* * * *} \\
(0.173)\end{array}$ & $\begin{array}{l}-3.540^{* * * *} \\
(0.204)\end{array}$ & $\begin{array}{l}-3.219^{* * * *} \\
(0.202)\end{array}$ & $\begin{array}{l}-3.972^{* * * *} \\
(0.262)\end{array}$ & $\begin{array}{l}-3.897^{* * * *} \\
(0.291)\end{array}$ & $\begin{array}{l}-3.643^{* * * *} \\
(0.294)\end{array}$ \\
\hline Mid-size (40-60th \%ile admit) & $\begin{array}{l}-2.160^{* * * *} \\
(0.192)\end{array}$ & $\begin{array}{l}-1.743^{* * *} \\
(0.213)\end{array}$ & $\begin{array}{l}-1.647^{* * *} \\
(0.212)\end{array}$ & $\begin{array}{l}-1.699^{* * * *} \\
(0.127)\end{array}$ & $\begin{array}{l}-1.651^{* * * *} \\
(0.139)\end{array}$ & $\begin{array}{l}-1.463^{* * * *} \\
(0.137)\end{array}$ & $\begin{array}{l}-2.407^{* * *} \\
(0.171)\end{array}$ & $\begin{array}{l}-1.954^{* * * *} \\
(0.177)\end{array}$ & $\begin{array}{l}-1.793^{* * *} \\
(0.185)\end{array}$ \\
\hline Medium-large (60-80th \%ile admit) & $\begin{array}{l}-1.380^{* * * *} \\
(0.188)\end{array}$ & $\begin{array}{l}-1.270^{* * *} \\
(0.215)\end{array}$ & $\begin{array}{l}-1.177^{* * *} \\
(0.212)\end{array}$ & $\begin{array}{l}-0.926^{* * * *} \\
(0.114)\end{array}$ & $\begin{array}{l}-1.072^{* * *} \\
(0.124)\end{array}$ & $\begin{array}{l}-0.987^{* * * *} \\
(0.120)\end{array}$ & $\begin{array}{l}-1.175^{* * *} \\
(0.138)\end{array}$ & $\begin{array}{l}-0.884^{* * * *} \\
(0.146)\end{array}$ & $\begin{array}{l}-0.754^{* * * *} \\
(0.154)\end{array}$ \\
\hline HHI (hosp $\leq 60 \mathrm{~min})$ & $\begin{array}{l}-0.994^{*} \\
(0.409)\end{array}$ & $\begin{array}{l}-2.753^{* * *} \\
(0.563)\end{array}$ & $\begin{array}{l}-2.931^{\text {**** }} \\
(0.636)\end{array}$ & $\begin{array}{l}-0.238 \\
(0.345)\end{array}$ & $\begin{array}{l}-3.184^{* * *} \\
(0.601)\end{array}$ & $\begin{array}{l}-3.702^{* * * *} \\
(0.691)\end{array}$ & $\begin{array}{l}-0.430 \\
(0.512)\end{array}$ & $\begin{array}{l}-6.103^{* * *} \\
(0.897)\end{array}$ & $\begin{array}{l}-7.416^{* * * *} \\
(1.070)\end{array}$ \\
\hline Hosp in system & $\begin{array}{l}0.203^{*} \\
(0.0876)\end{array}$ & $\begin{array}{l}0.280^{* * *} \\
(0.106)\end{array}$ & $\begin{array}{l}0.245^{*} \\
(0.111)\end{array}$ & $\begin{array}{l}0.0775 \\
(0.0744)\end{array}$ & $\begin{array}{l}0.111 \\
(0.0854)\end{array}$ & $\begin{array}{l}0.129 \\
(0.0846)\end{array}$ & $\begin{array}{l}0.136 \\
(0.106)\end{array}$ & $\begin{array}{l}0.183 \\
(0.123)\end{array}$ & $\begin{array}{l}0.229 \\
(0.126)\end{array}$ \\
\hline Adoption rate competitors - DxAngio & & $\begin{array}{l}8.345^{* * * *} \\
(0.229)\end{array}$ & $\begin{array}{l}9.320^{* * * *} \\
(0.275)\end{array}$ & & $\begin{array}{l}-0.260 \\
(0.191)\end{array}$ & $\begin{array}{l}-0.128 \\
(0.201)\end{array}$ & & $\begin{array}{l}-0.471 \\
(0.254)\end{array}$ & $\begin{array}{l}-0.410 \\
(0.262)\end{array}$ \\
\hline Adoption rate of competitors - PCI & & $\begin{array}{l}-0.250 \\
(0.394)\end{array}$ & $\begin{array}{l}-0.278 \\
(0.553)\end{array}$ & & $\begin{array}{l}8.608^{* * * *} \\
(0.255)\end{array}$ & $\begin{array}{l}10.81^{* * * *} \\
(0.399)\end{array}$ & & $\begin{array}{l}-0.481 \\
(0.370)\end{array}$ & $\begin{array}{l}-0.663 \\
(0.385)\end{array}$ \\
\hline Adoption rate of competitors - CABG & & $\begin{array}{l}-2.490^{* * *} \\
(0.490)\end{array}$ & $\begin{array}{l}-3.387^{\text {*** }} \\
(0.635)\end{array}$ & & $\begin{array}{l}-0.980^{* * * *} \\
(0.287)\end{array}$ & $\begin{array}{l}-2.622^{* * * *} \\
(0.389)\end{array}$ & & $\begin{array}{l}10.57^{* * * *} \\
(0.416)\end{array}$ & $\begin{array}{l}11.73^{* * * *} \\
(0.480)\end{array}$ \\
\hline Constant & $\begin{array}{l}-1.501 \\
(12.57) \\
\end{array}$ & $\begin{array}{l}-9.744 \\
(16.11) \\
\end{array}$ & $\begin{array}{l}-9.974 \\
(17.65) \\
\end{array}$ & $\begin{array}{l}15.82 \\
(11.23) \\
\end{array}$ & $\begin{array}{l}17.13 \\
(13.58) \\
\end{array}$ & $\begin{array}{l}41.84^{* * *} \\
(14.89)\end{array}$ & $\begin{array}{l}40.86^{*} \\
(16.81) \\
\end{array}$ & $\begin{array}{l}70.34^{* * * *} \\
(21.19) \\
\end{array}$ & $\begin{array}{l}70.98^{* * *} \\
(22.42)\end{array}$ \\
\hline Observations & 31,908 & 31,787 & 31,787 & 44,301 & 43,851 & 43,851 & 48,326 & 47,572 & 47,572 \\
\hline $\begin{array}{l}\text { ymean } \\
N_{\text {clust }}\end{array}$ & $\begin{array}{l}0.0238 \\
2,579\end{array}$ & $\begin{array}{l}0.0239 \\
2,574\end{array}$ & $\begin{array}{l}0.0239 \\
2,574\end{array}$ & $\begin{array}{l}0.0216 \\
3,397\end{array}$ & $\begin{array}{l}0.0213 \\
3,380\end{array}$ & $\begin{array}{l}0.0213 \\
3,380\end{array}$ & $\begin{array}{l}0.0096 \\
3,425\end{array}$ & $\begin{array}{l}0.0097 \\
3,409\end{array}$ & $\begin{array}{l}0.0097 \\
3,409\end{array}$ \\
\hline Pseudo-R $^{2}$ & 0.094 & 0.531 & 0.551 & 0.052 & 0.391 & 0.436 & 0.034 & 0.352 & 0.375 \\
\hline
\end{tabular}

Notes: Standard errors in parentheses, clustered at the hospital level. Control variables include: for hospital characteristics (population density of market, teaching status; network membership); pop. characteristics (total population; \% residents $<18,18-44,55-64,>=75$ by sex; $\%$ with high school degree, some college, college degree; grad. school; \% Hispanic, white, black; median income; \% median household income $\geq \$ 100 \mathrm{~K}, \%$ on public assistance). ${ }^{*} \mathrm{p}<0.05,{ }^{* *} \mathrm{p}<0.01,{ }^{* * *} \mathrm{p}<0.001$.

Sources: American Hospital Association's Annual Surveys of Hospitals (AHA) 1996-2014; U.S. Census (2000); American Community Survey (2010-2014); Medicare Provider Analysis and Review (MedPar) files for 100 percent of Medicare beneficiaries (1996-2014) 
Table 4. Prob. Adopting New Service by Hospital Ownership: Existing Population Access and Adoption by Competitors, 1997-2004.

\begin{tabular}{|c|c|c|c|c|c|c|}
\hline & (1) & (2) & (3) & (4) & (5) & (6) \\
\hline & $\begin{array}{c}\text { DxAngi } \\
\mathrm{o}\end{array}$ & $\begin{array}{c}\text { DxAngi } \\
\mathrm{o}\end{array}$ & PCI & PCI & CABG & CABG \\
\hline \multirow[t]{2}{*}{ For-profit hospital } & $\begin{array}{l}0.622^{* * *} \\
(0.181)\end{array}$ & $\begin{array}{l}0.881^{\text {**** }} \\
(0.206)\end{array}$ & $\underset{*}{0.490^{* *}}$ & $\underset{*}{0.704^{* *}}$ & $\underset{*}{0.637^{* *}}$ & $\underset{*}{1.222^{* *}}$ \\
\hline & & & $(0.132)$ & $(0.153)$ & $(0.180)$ & $(0.206)$ \\
\hline \multirow[t]{2}{*}{ Gov hospital } & - & $-0.489^{*}$ & - & $-0.495^{*}$ & - & $-0.583^{*}$ \\
\hline & $\begin{array}{c}0.527^{* * * *} \\
(0.160)\end{array}$ & $(0.233)$ & $\begin{array}{c}0.508^{* * * *} \\
(0.134)\end{array}$ & $(0.197)$ & $\begin{array}{c}0.929^{* * *} \\
(0.233)\end{array}$ & $(0.285)$ \\
\hline Adoption rate competitors - & $9.306^{* * *}$ & $9.444^{* * *}$ & -0.0815 & -0.296 & -0.396 & -0.398 \\
\hline DxAngio & $(0.277)$ & $(0.315)$ & $(0.201)$ & $(0.249)$ & $(0.258)$ & $(0.309)$ \\
\hline \multirow[t]{2}{*}{ Adoption rate of competitors - PCI } & -0.257 & 0.0558 & $10.81^{* * *}$ & $10.90^{* *}$ & -0.666 & -0.118 \\
\hline & $(0.565)$ & $(0.769)$ & $(0.402)$ & $(0.468)$ & $(0.387)$ & $(0.458)$ \\
\hline Adoption rate of competitors- & - & - & - & - & $11.63^{* *}$ & $12.05^{* *}$ \\
\hline \multirow[t]{2}{*}{ CABG } & $3.395^{* * *}$ & $3.682^{* * *}$ & $2.758^{* * * *}$ & $2.157^{* * *}$ & $*$ & $*$ \\
\hline & $(0.659)$ & $(0.897)$ & $(0.393)$ & $(0.470)$ & $(0.483)$ & $(0.571)$ \\
\hline \multirow[t]{2}{*}{$\%$ pop w/DxAngio access } & - & - & 0.207 & 0.164 & 0.0322 & 0.0706 \\
\hline & $\begin{array}{c}4.842^{* * * *} \\
(0.544)\end{array}$ & $\begin{array}{c}4.930^{* * * *} \\
(0.542)\end{array}$ & $(0.458)$ & $(0.454)$ & $(0.727)$ & $(0.742)$ \\
\hline \multirow[t]{2}{*}{$\%$ pop w/PCI access } & 0.00807 & 0.107 & - & - & 0.322 & 0.182 \\
\hline & $(0.854)$ & $(0.862)$ & $\begin{array}{c}9.061^{* * * *} \\
(0.880)\end{array}$ & $\begin{array}{c}8.904^{* * * *} \\
(0.862)\end{array}$ & $(0.738)$ & $(0.756)$ \\
\hline \multirow[t]{3}{*}{$\%$ pop w/CABG access } & $2.770^{* *}$ & $2.674^{* *}$ & $6.945^{* *}$ & $6.742^{* * *}$ & - & - \\
\hline & $(0.849)$ & $(0.848)$ & & & $3.602^{* * *}$ & $3.480^{* * *}$ \\
\hline & & & $(0.814)$ & $(0.796)$ & $(0.701)$ & $(0.711)$ \\
\hline \multirow[t]{3}{*}{ Smallest (lowest fifth admit) } & - & - & - & - & - & - \\
\hline & $4.669^{* * * *}$ & $4.712^{* * *}$ & $4.522^{* * * *}$ & $4.609^{* * *}$ & $3.974^{* * *}$ & $4.110^{* * *}$ \\
\hline & $(0.341)$ & $(0.337)$ & $(0.335)$ & $(0.338)$ & $(0.400)$ & $(0.433)$ \\
\hline \multirow[t]{3}{*}{ Small (20-40th \% ile admit) } & - & - & - & - & - & - \\
\hline & $3.089^{* * * *}$ & $3.139^{* * *}$ & $3.273^{* * * *}$ & $3.323^{* * *}$ & $3.781^{* * *}$ & $3.732^{* * *}$ \\
\hline & $(0.246)$ & $(0.243)$ & $(0.201)$ & $(0.201)$ & $(0.295)$ & $(0.289)$ \\
\hline \multirow[t]{3}{*}{ Mid-size (40-60th \%ile admit) } & - & - & - & - & - & - \\
\hline & $1.687^{* * *}$ & $1.744^{* * *}$ & $1.527^{* * * *}$ & $1.563^{* * *}$ & $1.931^{* * *}$ & $1.951^{* * *}$ \\
\hline & $(0.218)$ & $(0.220)$ & $(0.137)$ & $(0.137)$ & $(0.190)$ & $(0.190)$ \\
\hline \multirow[t]{3}{*}{ Medium-large (60-80th \% ile admit) } & - & - & - & - & - & - \\
\hline & $1.212^{* * * *}$ & $1.263^{* * *}$ & $1.032^{* * * *}$ & $1.069^{* * *}$ & $0.843^{* * *}$ & $0.855^{* * *}$ \\
\hline & $(0.217)$ & $(0.221)$ & $(0.120)$ & $(0.120)$ & $(0.153)$ & $(0.156)$ \\
\hline \multirow[t]{3}{*}{ HHI (hosp $\leq 60 \mathrm{~min})$} & - & - & - & - & - & - \\
\hline & $2.640^{* * * *}$ & $2.724^{* * *}$ & $3.698^{* * * *}$ & $3.743^{* * *}$ & $7.406^{* * *}$ & $7.213^{* * *}$ \\
\hline & $(0.626)$ & $(0.631)$ & $(0.703)$ & $(0.696)$ & $(1.071)$ & $(1.018)$ \\
\hline \multirow[t]{2}{*}{ FP*Comp adopting DxAngio } & & -0.900 & & $1.090^{*}$ & & 0.271 \\
\hline & & $(0.479)$ & & $(0.431)$ & & $(0.567)$ \\
\hline \multirow[t]{2}{*}{ FP*Comp adopting PCI } & & 0.0539 & & -0.859 & & -1.113 \\
\hline & & $(1.055)$ & & $(0.509)$ & & $(0.865)$ \\
\hline \multirow[t]{2}{*}{ FP*Comp. adopting CABG } & & 1.021 & & -1.205 & & -1.403 \\
\hline & & $(1.272)$ & & $(0.710)$ & & $(0.750)$ \\
\hline \multirow[t]{2}{*}{ Gov*Comp. adopting DxAngio } & & 0.590 & & -0.875 & & -0.541 \\
\hline & & $(0.510)$ & & $(0.587)$ & & $(0.989)$ \\
\hline \multirow[t]{2}{*}{ Gov*Comp. adopting PCI } & & -1.697 & & 0.886 & & -1.600 \\
\hline & & $(1.038)$ & & $(0.526)$ & & $(1.348)$ \\
\hline \multirow[t]{2}{*}{ Gov*Comp. adopting CABG } & & -0.669 & & -1.466 & & 0.466 \\
\hline & & $(1.400)$ & & $(0.813)$ & & $(0.955)$ \\
\hline \multirow[t]{2}{*}{ Constant } & -9.299 & -10.89 & $39.63^{* *}$ & $41.73^{* * *}$ & $68.65^{* *}$ & $66.53^{* *}$ \\
\hline & $(17.48)$ & $(17.38)$ & $(15.04)$ & $(14.95)$ & $(22.80)$ & $(23.10)$ \\
\hline Observations & 31,787 & 31,787 & 43,851 & 43,851 & 47,572 & 47,572 \\
\hline ymean & 0.0239 & 0.0239 & 0.0213 & 0.0213 & 0.0097 & 0.0097 \\
\hline N_clust & 2,574 & 2,574 & 3,380 & 3,380 & 3,409 & 3,409 \\
\hline Pseudo-R ${ }^{2}$ & 0.556 & 0.557 & 0.438 & 0.441 & 0.386 & 0.388 \\
\hline
\end{tabular}


Notes: Standard errors in parenthesis, clustered at the hospital level. Control variables include: for hospital characteristics (population density of market, teaching status; network membership); pop. characteristics (total population; $\%$ residents $<18,18-44,55-64,>=75$ by sex; $\%$ with high school degree, some college, college degree; grad. school; \% Hispanic, white, black; median income; \% median household income $\geq \$ 100 \mathrm{~K}, \%$ on public assistance). ${ }^{*} \mathrm{p}<0.05,{ }^{* *} \mathrm{p}<0.01,{ }^{* * *} \mathrm{p}<0.001$.

Sources: American Hospital Association's Annual Surveys of Hospitals (AHA) 1996-2014; U.S. Census (2000); American Community Survey (2010-2014); Medicare Provider Analysis and Review (MedPar) files for 100 percent of Medicare beneficiaries (1996-2014). 
Table 5. Probability of Adopting New Service by Ownership in Market: Existing Population Access and Adoption by Competitors, 1997-2004.

\begin{tabular}{|c|c|c|c|c|c|c|}
\hline & $(1)$ & (2) & (3) & (4) & (5) & (6) \\
\hline & DxAngio & DxAngio & PCI & PCI & CABG & CABG \\
\hline For-profit hospital & $\begin{array}{l}0.642 * * * \\
(0.182)\end{array}$ & $\begin{array}{l}0.912 * * * \\
(0.210)\end{array}$ & $\begin{array}{l}0.515 * * * \\
(0.131)\end{array}$ & $\begin{array}{l}0.720 * * * \\
(0.155)\end{array}$ & $\begin{array}{l}0.704 * * * \\
(0.182)\end{array}$ & $\begin{array}{l}1.309 * * * \\
(0.209)\end{array}$ \\
\hline Gov hospital & $\begin{array}{l}-0.522 * * \\
(0.160)\end{array}$ & $\begin{array}{l}-0.477^{*} \\
(0.232)\end{array}$ & $\begin{array}{l}-0.501 * * * \\
(0.133)\end{array}$ & $\begin{array}{l}-0.485^{*} \\
(0.197)\end{array}$ & $\begin{array}{l}-0.912 * * * \\
(0.234)\end{array}$ & $\begin{array}{l}-0.553 \\
(0.283)\end{array}$ \\
\hline High-FP market pen (over 10\%) & $\begin{array}{l}-0.109 \\
(0.146)\end{array}$ & $\begin{array}{l}-0.113 \\
(0.150)\end{array}$ & $\begin{array}{l}-0.127 \\
(0.134)\end{array}$ & $\begin{array}{l}-0.108 \\
(0.132)\end{array}$ & $\begin{array}{l}-0.422 * \\
(0.188)\end{array}$ & $\begin{array}{l}-0.461^{*} \\
(0.193)\end{array}$ \\
\hline $\begin{array}{l}\text { Adoption rate of competitors - } \\
\text { DxAngio }\end{array}$ & $\begin{array}{l}9.306 * * * \\
(0.276)\end{array}$ & $\begin{array}{l}9.449 * * * \\
(0.314)\end{array}$ & $\begin{array}{l}-0.0746 \\
(0.202)\end{array}$ & $\begin{array}{l}-0.287 \\
(0.250)\end{array}$ & $\begin{array}{l}-0.320 \\
(0.256)\end{array}$ & $\begin{array}{l}-0.311 \\
(0.307)\end{array}$ \\
\hline $\begin{array}{l}\text { Adoption rate of competitors - } \\
\text { PCI }\end{array}$ & $\begin{array}{l}-0.261 \\
(0.565)\end{array}$ & $\begin{array}{l}0.0605 \\
(0.769)\end{array}$ & $\begin{array}{l}10.81 * * * \\
(0.401)\end{array}$ & $\begin{array}{l}10.89 * * * \\
(0.467)\end{array}$ & $\begin{array}{l}-0.705 \\
(0.390)\end{array}$ & $\begin{array}{l}-0.178 \\
(0.463)\end{array}$ \\
\hline $\begin{array}{l}\text { Adoption rate of competitors - } \\
\text { CABG }\end{array}$ & $\begin{array}{l}-3.374 * * * \\
(0.660)\end{array}$ & $\begin{array}{l}-3.666^{* * * *} \\
(0.895)\end{array}$ & $\begin{array}{l}-2.730 * * * \\
(0.388)\end{array}$ & $\begin{array}{l}-2.126^{* * * *} \\
(0.464)\end{array}$ & $\begin{array}{l}11.69 * * * \\
(0.486)\end{array}$ & $\begin{array}{l}12.15^{* * * *} \\
(0.576)\end{array}$ \\
\hline$\%$ pop w/ DxAngio access & $\begin{array}{l}-4.815^{* * * *} \\
(0.545) \\
\end{array}$ & $\begin{array}{l}-4.903 * * * \\
(0.543) \\
\end{array}$ & $\begin{array}{l}0.232 \\
(0.456)\end{array}$ & $\begin{array}{l}0.186 \\
(0.453)\end{array}$ & $\begin{array}{l}0.0239 \\
(0.716) \\
\end{array}$ & $\begin{array}{l}0.0488 \\
(0.729) \\
\end{array}$ \\
\hline$\%$ pop w/PCI access & $\begin{array}{l}-0.00914 \\
(0.854)\end{array}$ & $\begin{array}{l}0.0940 \\
(0.863)\end{array}$ & $\begin{array}{l}-9.077 * * * \\
(0.879)\end{array}$ & $\begin{array}{l}-8.916 * * * \\
(0.863)\end{array}$ & $\begin{array}{l}0.268 \\
(0.732)\end{array}$ & $\begin{array}{l}0.144 \\
(0.747)\end{array}$ \\
\hline$\%$ pop w/CABG access & $\begin{array}{l}2.789 * * \\
(0.848)\end{array}$ & $\begin{array}{l}2.690^{* *} \\
(0.848)\end{array}$ & $\begin{array}{l}6.939 * * * \\
(0.809)\end{array}$ & $\begin{array}{l}6.738 * * * \\
(0.794)\end{array}$ & $\begin{array}{l}-3.538 * * * \\
(0.690)\end{array}$ & $\begin{array}{l}-3.425 * * * \\
(0.698)\end{array}$ \\
\hline Smallest (lowest fifth admit) & $\begin{array}{l}-4.663^{* * *} \\
(0.340)\end{array}$ & $\begin{array}{l}-4.708 * * * \\
(0.337)\end{array}$ & $\begin{array}{l}-4.516^{* * * *} \\
(0.335)\end{array}$ & $\begin{array}{l}-4.603^{* * *} \\
(0.339)\end{array}$ & $\begin{array}{l}-3.968 * * * \\
(0.399)\end{array}$ & $\begin{array}{l}-4.098^{* * * *} \\
(0.431)\end{array}$ \\
\hline Small (20-40th \% ile admit) & $\begin{array}{l}-3.086^{* * *} \\
(0.245) \\
\end{array}$ & $\begin{array}{l}-3.136^{* * * *} \\
(0.243)\end{array}$ & $\begin{array}{l}-3.263 * * * \\
(0.199)\end{array}$ & $\begin{array}{l}-3.314 * * * \\
(0.199)\end{array}$ & $\begin{array}{l}-3.750^{* * *} \\
(0.288)\end{array}$ & $\begin{array}{l}-3.693 * * * * \\
(0.283)\end{array}$ \\
\hline Mid-size (40-60th \%ile admit) & $\begin{array}{l}-1.686^{* * *} \\
(0.217)\end{array}$ & $\begin{array}{l}-1.746 * * * \\
(0.220)\end{array}$ & $\begin{array}{l}-1.527 * * * \\
(0.138)\end{array}$ & $\begin{array}{l}-1.563^{* * * *} \\
(0.137)\end{array}$ & $\begin{array}{l}-1.929 * * * \\
(0.189)\end{array}$ & $\begin{array}{l}-1.951^{* * *} \\
(0.189)\end{array}$ \\
\hline $\begin{array}{l}\text { Medium-large (60-80th \% ile } \\
\text { admit) }\end{array}$ & $\begin{array}{l}-1.210 * * * \\
(0.217)\end{array}$ & $\begin{array}{l}-1.262 * * * \\
(0.221)\end{array}$ & $\begin{array}{l}-1.031 * * * \\
(0.120)\end{array}$ & $\begin{array}{l}-1.067 * * * \\
(0.120)\end{array}$ & $\begin{array}{l}-0.842 * * * \\
(0.153)\end{array}$ & $\begin{array}{l}-0.854 * * * \\
(0.157)\end{array}$ \\
\hline HHI (hosp $\leq 60 \mathrm{~min})$ & $\begin{array}{l}-2.748 * * * \\
(0.637)\end{array}$ & $\begin{array}{l}-2.838 * * * \\
(0.645)\end{array}$ & $\begin{array}{l}-3.840 * * * \\
(0.721)\end{array}$ & $\begin{array}{l}-3.859 * * * \\
(0.712)\end{array}$ & $\begin{array}{l}-7.954 * * * \\
(1.116)\end{array}$ & $\begin{array}{l}-7.755^{* * *} \\
(1.042)\end{array}$ \\
\hline FP*Comp adopting DxAngio & & $\begin{array}{l}-0.918 \\
(0.479) \\
\end{array}$ & & $\begin{array}{l}1.076^{*} \\
(0.431) \\
\end{array}$ & & $\begin{array}{l}0.248 \\
(0.559) \\
\end{array}$ \\
\hline FP*Comp adopting PCI & & $\begin{array}{l}0.0382 \\
(1.059)\end{array}$ & & $\begin{array}{l}-0.832 \\
(0.506)\end{array}$ & & $\begin{array}{l}-1.006 \\
(0.853)\end{array}$ \\
\hline FP*Comp. adopting CABG & & $\begin{array}{l}1.021 \\
(1.273)\end{array}$ & & $\begin{array}{l}-1.219 \\
(0.706)\end{array}$ & & $\begin{array}{l}-1.528^{*} \\
(0.742)\end{array}$ \\
\hline Gov*Comp. adopting DxAngio & & $\begin{array}{l}0.573 \\
(0.509)\end{array}$ & & $\begin{array}{l}-0.870 \\
(0.589)\end{array}$ & & $\begin{array}{l}-0.403 \\
(0.985)\end{array}$ \\
\hline Gov*Comp. adopting PCI & & $\begin{array}{l}-1.709 \\
(1.042)\end{array}$ & & $\begin{array}{l}0.883 \\
(0.529)\end{array}$ & & $\begin{array}{l}-1.902 \\
(1.377)\end{array}$ \\
\hline Gov*Comp. adopting CABG & & $\begin{array}{l}-0.637 \\
(1.411)\end{array}$ & & $\begin{array}{l}-1.483 \\
(0.813) \\
\end{array}$ & & $\begin{array}{l}0.621 \\
(0.967) \\
\end{array}$ \\
\hline Constant & $\begin{array}{l}-8.038 \\
(17.59)\end{array}$ & $\begin{array}{l}-9.579 \\
(17.49)\end{array}$ & $\begin{array}{l}42.19^{* *} \\
(15.18)\end{array}$ & $\begin{array}{l}43.86^{* *} \\
(15.18)\end{array}$ & $\begin{array}{l}74.88^{* * *} \\
(22.88)\end{array}$ & $\begin{array}{l}74.54 * * \\
(23.25)\end{array}$ \\
\hline Observations & 31,787 & 31,787 & 43,851 & 43,851 & 47,572 & 47,572 \\
\hline ymean & 0.0239 & 0.0239 & 0.0213 & 0.0213 & 0.0097 & 0.0097 \\
\hline N_clust & 2,574 & 2,574 & 3,380 & 3,380 & 3,409 & 3,409 \\
\hline Pseudo-R ${ }^{2}$ & 0.556 & 0.557 & 0.439 & 0.441 & 0.388 & 0.390 \\
\hline
\end{tabular}

Notes: Standard errors in parentheses, clustered at the hospital level. Control variables include, for hospital characteristics (population density of market, teaching status; network membership); pop. characteristics (total population; $\%$ residents $<18,18-44,55-64,\rangle=75$ by sex; $\%$ with high school degree, some college, college degree; grad. school; \% Hispanic, white, black; median income; \% median household income $\geq \$ 100 \mathrm{~K}, \%$ on public assistance). ${ }^{*} \mathrm{p}<0.05,{ }^{* * *} \mathrm{p}<0.01,{ }^{* * * *} \mathrm{p}<0.001$.

Sources: American Hospital Association's Annual Surveys of Hospitals (AHA) 1996-2014; U.S. Census (2000); American Community Survey (2010-2014); Medicare Provider Analysis and Review (MedPar) files for 100 percent of Medicare beneficiaries (1996-2014) 
Table 6. Prob. Adopting New Service by FP Market \& Competitor Adoption (1997-2004)

\begin{tabular}{|c|c|c|c|c|c|c|}
\hline & (1) & (2) & (3) & (4) & (5) & (6) \\
\hline & DxAngio & DxAngio & PCI & PCI & CABG & CABG \\
\hline \multirow{2}{*}{ For-profit hospital } & $1.277^{* * *}$ & $1.199^{* * *}$ & $1.043^{* * *}$ & $0.985^{* * *}$ & $1.905^{* * *}$ & $1.864^{* * *}$ \\
\hline & $(0.262)$ & $(0.279)$ & $(0.190)$ & $(0.196)$ & $(0.233)$ & $(0.241)$ \\
\hline \multirow[t]{2}{*}{ Gov hospital } & $-0.686^{*}$ & $-0.748^{*}$ & $-0.717^{* *}$ & $-0.758^{* * *}$ & $-0.949^{*}$ & $-1.047^{*}$ \\
\hline & $(0.286)$ & $(0.305)$ & $(0.251)$ & $(0.269)$ & $(0.452)$ & $(0.492)$ \\
\hline \multirow{2}{*}{ High-FP market } & 0.333 & $0.649^{*}$ & 0.315 & 0.510 & 0.318 & 0.724 \\
\hline & $(0.294)$ & $(0.329)$ & $(0.263)$ & $(0.302)$ & $(0.524)$ & $(0.544)$ \\
\hline \multirow[t]{2}{*}{ FP*high-FP market } & $-0.930^{*}$ & $-0.981^{*}$ & $-0.895^{* *}$ & $-0.886^{* * *}$ & $-1.590^{* *}$ & $-1.671^{* *}$ \\
\hline & $(0.380)$ & $(0.383)$ & $(0.313)$ & $(0.318)$ & $(0.548)$ & $(0.558)$ \\
\hline \multirow{2}{*}{ GOV*high-FP market } & -0.387 & -0.376 & -0.352 & -0.324 & -0.534 & -0.517 \\
\hline & $(0.324)$ & $(0.321)$ & $(0.275)$ & $(0.284)$ & $(0.529)$ & $(0.535)$ \\
\hline Adoption rate of competitors & $9.455^{* * * *}$ & $9.819^{* * * *}$ & -0.307 & -0.0920 & -0.398 & -0.00408 \\
\hline - DxÁngio & $(0.315)$ & $(0.348)$ & $(0.251)$ & $(0.293)$ & $(0.310)$ & $(0.346)$ \\
\hline Adoption rate of competitors & 0.0252 & -0.378 & $10.89^{* * *}$ & $10.98^{* * *}$ & -0.214 & -0.500 \\
\hline - PCI & $(0.768)$ & $(0.930)$ & $(0.468)$ & $(0.523)$ & $(0.458)$ & $(0.557)$ \\
\hline Adoption rate of competitors & $-3.662^{* * * *}$ & $-3.283^{* *}$ & $-2.121^{* * * *}$ & $-1.684^{* *}$ & $12.24^{* * * *}$ & $12.93^{* * * *}$ \\
\hline - CABG & $(0.893)$ & $(1.060)$ & $(0.463)$ & $(0.532)$ & $(0.569)$ & $(0.676)$ \\
\hline \multirow[t]{2}{*}{$\%$ pop w/ DxAngio access } & $-4.937^{* * *}$ & $-5.115^{* * *}$ & 0.144 & 0.0747 & -0.107 & -0.300 \\
\hline & $(0.549)$ & $(0.560)$ & $(0.451)$ & $(0.457)$ & $(0.727)$ & $(0.749)$ \\
\hline \multirow[t]{2}{*}{$\%$ pop w/PCI access } & 0.199 & 0.271 & $-8.856^{* * *}$ & $-8.958^{* * *}$ & 0.397 & 0.557 \\
\hline & $(0.871)$ & $(0.893)$ & $(0.862)$ & $(0.866)$ & $(0.746)$ & $(0.764)$ \\
\hline \multirow{2}{*}{$\%$ pop w/CABG access } & $2.610^{* * *}$ & $2.624^{* *}$ & $6.668^{* * * *}$ & $6.768^{* * *}$ & $-3.639^{* * * *}$ & $-3.806^{* * * *}$ \\
\hline & $(0.850)$ & $(0.889)$ & $(0.794)$ & $(0.801)$ & $(0.702)$ & $(0.713)$ \\
\hline \multirow[t]{2}{*}{ FP*Comp adopting DxAngio } & -0.842 & -0.493 & $1.175^{* *}$ & $1.249^{* *}$ & 0.498 & 0.708 \\
\hline & $(0.473)$ & $(0.498)$ & $(0.425)$ & $(0.434)$ & $(0.539)$ & $(0.548)$ \\
\hline \multirow[t]{2}{*}{ FP*Comp adopting PCI } & -0.00190 & -0.237 & -0.662 & -0.659 & -0.967 & -1.142 \\
\hline & $(1.079)$ & $(1.089)$ & $(0.516)$ & $(0.520)$ & $(0.826)$ & $(0.820)$ \\
\hline \multirow{2}{*}{ FP*Comp. adopting CABG } & 1.093 & 1.224 & -1.301 & -0.863 & $-1.491^{*}$ & -1.127 \\
\hline & $(1.282)$ & $(1.281)$ & $(0.692)$ & $(0.692)$ & $(0.723)$ & $(0.731)$ \\
\hline Gov*Comp. adopting & 0.631 & 0.708 & -0.927 & -0.934 & -0.751 & -0.579 \\
\hline DxAngio & $(0.516)$ & $(0.518)$ & $(0.571)$ & $(0.565)$ & $(1.058)$ & $(1.036)$ \\
\hline \multirow[t]{2}{*}{ Gov*Comp. adopting PCI } & -1.541 & -1.498 & 1.019 & $1.070^{*}$ & -1.149 & -1.645 \\
\hline & $(1.032)$ & $(1.065)$ & $(0.526)$ & $(0.524)$ & $(1.469)$ & $(1.509)$ \\
\hline \multirow[t]{2}{*}{ Gov*Comp. adopting CABG } & -0.964 & -0.873 & -1.532 & -1.349 & 0.350 & 0.978 \\
\hline & $(1.420)$ & $(1.422)$ & $(0.812)$ & $(0.794)$ & $(0.945)$ & $(0.996)$ \\
\hline FPMarket*Comp adopting & & $-0.866^{*}$ & & -0.293 & & -0.753 \\
\hline DxAngio & & $(0.411)$ & & $(0.379)$ & & $(0.511)$ \\
\hline FPMarket*Comp adopting & & 0.804 & & -0.142 & & 0.788 \\
\hline PCI & & $(1.055)$ & & $(0.476)$ & & $(0.789)$ \\
\hline FPMarket*Comp adopting & & -0.732 & & -1.133 & & $-1.561^{*}$ \\
\hline CABG & & $(1.237)$ & & $(0.607)$ & & $(0.749)$ \\
\hline Constant & -8.733 & -11.46 & $43.13^{* *}$ & $44.34^{* *}$ & $70.60^{* *}$ & $73.31^{* * *}$ \\
\hline & (17.34) & (17.43) & $(15.10)$ & $(15.00)$ & (22.67) & (22.23) \\
\hline Observations & 31,787 & 31,787 & 43,851 & 43,851 & 47,572 & 47,572 \\
\hline ymean & 0.0239 & 0.0239 & 0.0213 & 0.0213 & 0.0097 & 0.0097 \\
\hline N_clust & 2,574 & 2,574 & 3,380 & 3,380 & 3,409 & 3,409 \\
\hline Pseudo-R $^{2}$ & 0.558 & 0.559 & 0.442 & 0.443 & 0.395 & 0.398 \\
\hline
\end{tabular}

Notes: Standard errors in parentheses, clustered at the hospital level. Control variables include, for hospital characteristics (population density of market, teaching status; network membership; size quintiles by admissions); pop. and market characteristics (total population; $\%$ residents $<18,18-44,55-64, \geq 75$ by sex; $\%$ with high school degree, some college, college degree; grad. school; \% Hispanic, white, black; median income; \% median household income $\geq \$ 100 \mathrm{~K}, \%$ on public assistance; HHI). ${ }^{*} \mathrm{p}<0.05,{ }^{* *} \mathrm{p}<0.01,{ }^{* * *} \mathrm{p}<0.001$. High FP penetration $=$ markets $\geq 10$ percent fp hospital penetration.

Sources: American Hospital Association's Annual Surveys of Hospitals (AHA) 1996-2014; U.S. Census (2000); American Community Survey (2010-2014); Medicare Provider Analysis and Review (MedPar) files for 100 percent of Medicare beneficiaries (1996-2014) 